\title{
Attenuation of oxidative stress and cardioprotective effects of zinc supplementation in experimental diabetic rats
}

\author{
Susmita Barman and Krishnapura Srinivasan* \\ Department of Biochemistry and Nutrition, Central Food Technological Research Institute (CSIR), Mysore 570 020, India \\ (Submitted 19 September 2016 - Final revision received 19 December 2016 - Accepted 11 January 2017-First published online 1 March 2017)
}

\begin{abstract}
Oxidative stress plays a major role in the pathogenesis of diabetes mellitus, which further exacerbates damage of cardiac, hepatic and other tissues. We have recently reported that Zn supplementation beneficially modulates hyperglycaemia and hypoinsulinaemia, with attendant reduction of associated metabolic abnormalities in diabetic rats. The present study assessed the potential of $\mathrm{Zn}$ supplementation in modulating oxidative stress and cardioprotective effects in diabetic rats. Diabetes was induced in Wistar rats with streptozotocin, and groups of diabetic rats were treated with 5- and 10-fold dietary $\mathrm{Zn}$ interventions ( 0.19 and $0.38 \mathrm{~g} \mathrm{Zn/kg} \mathrm{diet)} \mathrm{for} 6$ weeks. The markers of oxidative stress, antioxidant enzyme activities and concentrations of antioxidant molecules, lipid profile, and expressions of fibrosis and pro-apoptotic factors in the cardiac tissue were particularly assessed. Supplemental $\mathrm{Zn}$ showed significant attenuation of diabetes-induced oxidative stress in terms of altered antioxidant enzyme activities and increased the concentrations of antioxidant molecules. Hypercholesterolaemia and hyperlipidaemia were also significantly countered by $\mathrm{Zn}$ supplementation. Along with attenuated oxidative stress, $\mathrm{Zn}$ supplementation also showed significant cardioprotective effects by altering the mRNA expressions of fibrosis and pro-apoptotic factors (by $>50 \%$ ). The expression of lipid oxidative marker 4-hydroxy-2-nonenal (4-HNE) protein in cardiac tissue of diabetic animals was rectified (68\%) by Zn supplementation. Elevated cardiac and hepatic markers in circulation and pathological abnormalities in cardiac and hepatic tissue architecture of diabetic animals were ameliorated by dietary $\mathrm{Zn}$ intervention. The present study indicates that $\mathrm{Zn}$ supplementation can attenuate diabetes-induced oxidative stress in circulation as well as in cardiac and hepatic tissues.
\end{abstract}

Key words: Zinc supplementation: Diabetes mellitus: Oxidative stress: Cardioprotective effects: Antioxidant enzymes: Fibrosis and apoptosis markers

Oxidative stress resulting from an overproduction of reactive oxygen/nitrogen radicals along with diminished endogenous antioxidant systems generally leads to the development of degenerative diseases ${ }^{(1,2)}$. Animal studies have indicated that prolonged extracellular and intracellular high concentrations of glucose result in oxidative stress due to an imbalance between pro-oxidants and antioxidants ${ }^{(3)}$. Glucose is oxidised to an enediol radical anion in a transition metal-dependent reaction, and is further converted into reactive ketoaldehydes and to superoxide anions, which undergo dismutation to hydrogen peroxide leading to the production of extremely reactive hydroxyl radicals in the presence of transition metals ${ }^{(4)}$.

Reactive oxygen radicals and oxidative stress are important features of CVD including atherosclerosis and related vascular diseases, inflammatory diseases, mutagenesis and cancer, neurodegeneration and ageing ${ }^{(5)}$. Cellular signal transduction pathways are influenced by the $\mathrm{Zn}$ and redox status of the cell. Chronic diseases including diabetes mellitus caused by the apoptosis of pancreatic $\beta$-cells as well as insulin resistance in type 2 diabetes and diabetic cardiomyopathy have been associated with increased oxidative stress as well as perturbations in $\mathrm{Zn}$ homoeostasis. Several mechanisms such as glucose autoxidation, protein glycation and formation of advanced glycation end products, and stimulated polyol pathway seem to contribute to the genesis of oxidative stress, both in experimental diabetes and in type- 1 and type- 2 diabetic patients ${ }^{(6)}$.

Uncompromised diabetes leads to dyshomoeostasis of $\mathrm{Zn}^{(7)}$, and chronic deprivation of $\mathrm{Zn}$ generally results in increased sensitivity to oxidative stress. We have recently studied the potential of $\mathrm{Zn}$ supplementation in modulating diabetes in streptozotocin-administered rats $^{(8)}$. Zn supplementation showed control on hyperglycaemia and hypoinsulinaemia in diabetic rats, by reducing the associated metabolic abnormalities such as protein glycosylation, glucosuria and proteinuria ${ }^{(8)}$. In eukaryotic cells, the mitochondrial respiratory chain, microsomal cytochrome $\mathrm{P}_{450}$ enzymes, flavoprotein oxidases and peroxisomal fatty acid metabolism are the most significant intracellular sources of reactive oxygen species (ROS). Zn plays an inhibitory role on

Abbreviations: 4-HNE, 4-hydroxy-2-nonenal; Bax, BCL2 associated X protein; Bcl-2, B-cell lymphoma 2; CAT, catalase; CK-MB, creatine phosphokinase-MB; GPx, glutathione peroxidase; GR, glutathione reductase; GST, glutathione-S-transferase; LPO, lipid peroxidation; PAS, periodic acid Schiff; PC, protein carbonyl; ROS, reactive oxygen species; SOD, superoxide dismutase.

* Corresponding author: Dr K. Srinivasan, fax +91 821251 7233, email ksri.cftri@gmail.com 
$\mathrm{NADPH}$ oxidases (a group of plasma membrane-associated enzymes), which catalyse the production of $\mathrm{O}_{2} \cdot$ from oxygen. The dismutation of $\mathrm{O}_{2}^{\circ}$ to $\mathrm{H}_{2} \mathrm{O}_{2}$ is catalysed by superoxide dismutase (SOD), which contains $\mathrm{Cu}$ and $\mathrm{Zn}$. $\mathrm{Zn}$ is known to induce the formation of cysteine-rich metallothionein, an excellent scavenger of ${ }^{\bullet} \mathrm{OH}^{(9)}$. Zn-deprivation studies carried out to understand whether $\mathrm{Zn}$ has a physiological role as an antioxidant have generally indicated that $\mathrm{Zn}$ deprivation renders an organism more susceptible to injury induced by a variety of oxidative stresses ${ }^{(10)}$.

The apparent inter-relationship between $\mathrm{Zn}$ and redox effects in a variety of biochemical pathways as well as the high prevalence of $\mathrm{Zn}$ deficiency worldwide have generated interest in the possible therapeutic benefit of $\mathrm{Zn}$ supplementation for human health. The possible beneficial effects of $\mathrm{Zn}$ supplementation on diabetes complications such as CVD are also contemplated. Several studies have shown that $\mathrm{Zn}$ supplementation has potential antioxidant as well as cardioprotective effects and promotes healthy lipid profile ${ }^{(6,11)}$. However, these studies have been inconclusive. Further studies are warranted to identify the exact biological mechanisms responsible for the heterogeneous results. It is also important to conduct further well-designed randomised control trials to evaluate the potential beneficial effects of $\mathrm{Zn}$ supplementation in ameliorating diabetes-induced oxidative stress and diabetic cardiomyopathy and hepatic damage. Therefore, the present animal study was carried out to evaluate the influence of $\mathrm{Zn}$ supplementation on oxidative stress associated with diabetes with particular focus on heart and liver tissues.

\section{Methods}

\section{Chemicals}

Streptozotocin, glucose oxidase, o-dianisidine, horse radish peroxidase (HRP), bovine serum albumin, cholesterol, dipalmitoylphosphatidylcholine, triolein, glutathione reductase (GR), glutathione reduced, glutathione oxidised, $t$-butyl hydroxyperoxide, xanthine oxidase, xanthine, cytochrome $\mathrm{C}$ and $o$-phthalaldehyde were procured from Sigma-Aldrich Chemical Co. 1-Chloro-2,4-dinitrobenzoic acid, NADP (reduced form (NADPH) and Bernhardt-Tommarelli modified salt mixture were procured from SISCO Research Laboratories. Casein was obtained from Nimesh Corporation. Maize starch, cane sugar powder and refined groundnut oil were purchased from the local market. Alanine aminotransferase (ALT), aspartate aminotransferase (AST), LDH and creatine phosphokinase-MB (CK-MB) kits were purchased from Agappe Diagnostics Ltd. All primers (listed in Table 1) used for PCR amplifications were procured from Sigma-Aldrich Chemical Co., and antibodies (Anti-beta
Actin antibody-ab8227 and Anti-4-hydroxynonenal antibodyab46545) were from Abcam. All other chemicals and solvents used in this study were of analytical grade.

\section{Experimental animals}

The animal study was conducted with due authorisation from the Institutional Animal Ethics Committee (CFTRI, Mysore), and all precautions were taken to reduce pain and discomfort to the animals. Adult, female, 12-week-old Wistar rats weighing 140-150g used for the experiment were procured from the Experimental Animal Production Facility of this Institute. Rats were individually housed in stainless-steel cages at ambient temperature $\left(25 \pm 2^{\circ} \mathrm{C}\right)$ and humidity $(40-70 \%)$ with a $12 \mathrm{~h}$ light12 hour dark cycle. Rats had free access to diet and water $\mathrm{ad}$ libitum. Diabetes was induced by a single intraperitoneal injection of streptozotocin $(40 \mathrm{mg} / \mathrm{kg}$ body weight as $1 \mathrm{ml}$ freshly prepared solution in $0 \cdot 1 \mathrm{M}$-citrate buffer, $\mathrm{pH} 4 \cdot 5$ ). Animals were given $5 \%$ glucose water and ad libitum basal diet for $48 \mathrm{~h}$ following streptozotocin administration to prevent drug-induced hypoglycaemic mortality. After 1 week of streptozotocin induction, fasting blood glucose levels were measured by the glucose oxidase method ${ }^{(12)}$ after drawing blood from the retro-orbital plexus of overnight fasted rats. Rats having fasting blood glucose levels $>15 \mathrm{mmol} / \mathrm{l}$ were considered diabetic for further studies.

\section{Diets and animal treatment}

A normal basal diet (AIN-76) was prepared according to the American Institute of Nutrition rodent diet. Experimental diets were prepared by amending the basal diet with the addition of Zn salt (zinc carbonate). Zn supplementation was made such that it conforms to five times $(0.19 \mathrm{~g} / \mathrm{kg}$ diet $)$ and ten times $(0 \cdot 38 \mathrm{~g} / \mathrm{kg}$ diet $)$ the RDA. Rats were divided into six groups, out of which three groups were diabetic ( $n$ 12/group) and the other three groups were normal ( $n$ 8/group). One group of diabetic animals and one group of normal animals were maintained on a semisynthetic basal diet. The two experimental diets consisted of five times (Zn-dose 1) and ten times (Zn-dose 2) Zn supplementation. The animals were maintained on these dietary interventions for 6 weeks. The six animal groups were as follows: (1) normal control (N), (2) normal $+\mathrm{Zn}$ (dose 1), (3) normal $+\mathrm{Zn}$ (dose 2), (4) diabetic control (D), (5) diabetic $+\mathrm{Zn}($ dose 1) and (6) Diabetic $+\mathrm{Zn}$ (dose 2).

At the end of the experiment, rats were fasted overnight and killed under euthanasia by exsanguination from the heart. Blood samples were collected in heparinised tubes by puncturing the heart, and plasma was separated by centrifugation and stored at

Table 1. Sequences of primers used in this study

\begin{tabular}{lll}
\hline Genes & Sequence 5'-3' (forward) & Sequence 5'-3' (reverse) \\
\hline Fibronectin & GTGATCTACGAGGGACAGC & GCTGGTGGTGAAGTCAAAG \\
Type IV collagen & GCCCTACGTTAGCAGATGTACC & TATAAATGGACTGGCTCGGAAT \\
Bax & CGAGCTGATCAGAACCATCA & CTCAGCCCATCTTCTTCCAG \\
Bcl-2 & GGGATGCCTTTGGGAACTA & CTCACTTGTGGCCCAGGTAT \\
$\beta$-Actin & AGGCCCCTCTGAACCCTAAG & CCAGAGGCATACAGGGACAA \\
\hline
\end{tabular}

Bax, BCL2 associated X protein; Bcl-2, B-cell lymphoma 2. 
$-80^{\circ} \mathrm{C}$ until further analysis. The heart and liver were quickly excised, weighed and stored at $-80^{\circ} \mathrm{C}$ until analysis. A portion of the heart and the liver were homogenised in ice-cold $50 \mathrm{~mm}$ phosphate buffer ( $\mathrm{pH} 7.4$ ) using Teflon homogeniser to prepare a $10 \%(\mathrm{w} / \mathrm{v})$ tissue homogenate. An aliquot of the tissue homogenate was centrifuged at $15000 \mathrm{~g}$ for $15 \mathrm{~min}$ at $4^{\circ} \mathrm{C}$, and the cytosolic supernatant was used to determine all biochemical parameters. Lysis buffer was used for proteomic studies (Western blot). Portions of the heart and liver were stored in RNA latter for real-time (RT) PCR and in 10\% formalin for histopathology and immunohistochemistry studies.

\section{Reactive oxygen species, lipid peroxidation and protein carbonyl content}

ROS formation in plasma and tissue homogenates was quantified from the dichlorofluorescein standard curve as described by LeBel et $a l^{(13)}$ and Driver et $a l^{(14)}$, and data are expressed as pmol of dichlorofluorescein formed/min per mg protein. Plasma lipid peroxidation (LPO) concentrations were measured as thiobarbituric acid reactive substances according to Yagi ${ }^{(15)}$. Lipid peroxides in the heart and liver were assayed by determining the malondialdehyde (MDA) concentration spectrophotometrically (Shimadzu UV-1800; Shimadzu Corporation) using the method of Ohkawa et al. ${ }^{(16)}$. Protein carbonyl (PC) levels were quantified as described by Reznick \& Packer ${ }^{(17)}$, and the results are expressed in nmol carbonyls/mg protein $(\mathrm{e}-22000 \mathrm{M} / \mathrm{cm})$.

\section{Activities of antioxidant enzymes}

Heart and liver homogenates and plasma were assayed for the activities of various antioxidant enzymes. SOD activity was evaluated by quantitating the inhibition of cytochrome $\mathrm{C}$ reduction in the xanthine-xanthine oxidase system ${ }^{(18)}$. Catalase (CAT) activity was assayed following the rate of decomposition of hydrogen peroxide $^{(19)}$. Glutathione peroxidase (GPx) was evaluated using NADPH oxidation ${ }^{(20)}$. GR activity was measured by following the oxidation of NADPH by oxidised glutathione ${ }^{(21)}$. Glutathione$S$-transferase (GST) activity was analysed by determining the chloro-dinitrobenzene-glutathione conjugate formed using 1-chloro-2,4-dinitrobenzene as the substrate ${ }^{(22)}$.

\section{Antioxidant molecules}

Glutathione was estimated using Ellman's reagent ${ }^{(23)}$. Ascorbic acid was quantitated spectrophotometrically by measuring the 2,4-dinitrophenylhydrazine derivative of dehydroascorbic acid ${ }^{(24)}$.

\section{Cardiac and hepatic marker enzymes}

Activities of alkaline phosphatase (ALP), AST and ALT in plasma and of CK-MB in plasma and heart were assayed using appropriate commercial diagnostic kits. The enzyme activities were expressed as units per litre or units per mg protein. The activity of plasma ALP was estimated by following the method of Kind \& King ${ }^{(25)}$. Protein was quantified by using Folin phenol reagent ${ }^{(26)}$.

\section{Lipid profile}

Heart and liver lipid samples were extracted by the procedure of Folch et $a l .{ }^{(27)}$. Cholesterol was quantified by the method of Searcy \& Bergquist ${ }^{(28)}$. The HDL- and LDL-cholesterol levels in plasma were estimated according to Warnick \& Albers ${ }^{(29)}$. Phospholipid concentration was estimated by the ferrous ammonium thiocyanate method ${ }^{(30)}$. TAG were estimated according to the method described by Fletcher ${ }^{(31)}$. The atherogenicity index was calculated as (total cholesterol-HDL-cholesterol)/HDL-cholesterol.

Methylation of fatty acids of heart lipid extracts was carried out following the protocol of Bowyer et al. ${ }^{(32)}$. The fatty acid methyl esters were analysed by GC (PerkinElmer) using carbowax column GC-C 580. The column temperature was controlled to increase from 170 to $240^{\circ} \mathrm{C}$ at $6^{\circ} \mathrm{C} / \mathrm{min}$. Individual fatty acids were identified according to their retention times by comparing with standards provided by Nu-Check Prep. The percentage of each fatty acid was calculated from the areas under the chromatogram peaks using Shimadzu C-R6A Chromatopac software.

\section{Real-time PCR}

Total RNA was isolated from cardiac tissues (stored in RNA later) as per the manufacturer's protocol using TRI Reagent kit (total RNA isolation reagent). The quantity and quality of total RNA in samples were determined using NanoDrop ND-1000 spectrophotometer (NanoDrop Technologies) in ng/ $\mu$ l. Complementary DNA (cDNA) was synthesised using Verso cDNA synthesis kit (Thermo Fisher Scientific Inc.) following the instructions given by the manufacturer. The RNA expression using various primers was computed using Bio-Rad CFX96 Touch RT-PCR and SYBR green PCR reagents (Bio-Rad Laboratories). The relative expression was determined considering $C_{t}$ value. The fold changes were considered by comparing the $C_{t}$ value of $\beta$-actin amplified with samples in order to normalise quantification.

\section{Western blot analysis}

Samples were homogenised using ice-cold lysis buffer ( $\mathrm{pH} 7 \cdot 5$ ). Each lysate of $50 \mu \mathrm{g}$ was resolved by $10 \%$ SDS-PAGE, transferred onto PVDF membranes (Pall Life Sciences) and immunoblotted with the specified polyclonal antibody for rat $(\beta$-actin and 4-hydroxy-2-nonenal (4-HNE)) followed by an appropriate HRPconjugated secondary antibody. Western blot signal was developed according to standard procedures using ECL chemiluminescence reagents (Sigma Chemicals Co.).

\section{Histopathology of heart and liver tissue}

Fresh heart and liver tissues were excised and fixed in $10 \%$ formalin at room temperature. The fixative was removed by washing under running tap water overnight. After dehydration through a graded series of alcohol, the tissues were washed in methyl benzoate, and embedded in paraffin wax. Sections were cut into 5- $\mu \mathrm{m}$-thick slices, and were individually stained with haematoxylin-eosin (H\&E) to examine the morphological condition of the tissue. Masson's trichrome stain was used to detect collagen fibres, and periodic acid Schiff (PAS) was used 
for assessing glycogen deposition. After repeated dehydration and cleaning, the sections were mounted and examined under light microscope with a magnification of $40 \times$ attached with a digital camera (Olympus BX40; Olympus Optical Co., Ltd) for histological changes.

\section{Statistical analysis}

Values are expressed as means with their standard errors of eight rats. Statistical analyses were carried out using Prism 6.0 (Graph-Pad Software). Results were analysed, and the significant difference level was calculated using the Bonferroni selective comparison test; comparisons between groups were carried out by means of one-way ANOVA. The differences were considered significant at $P<0.05$.

\section{Results}

The weights of the heart and liver of diabetic rats were increased by 44 and $63 \%$, respectively, compared with normal control rats (Fig. 1). Diabetic rats treated with supplemental $\mathrm{Zn}$-containing diets $(\mathrm{D}+\mathrm{Zn}-1$ and $\mathrm{D}+\mathrm{Zn}-2)$ showed significant $(P<0 \cdot 05)$ restoration (17 and $18 \%$ in $\mathrm{D}+\mathrm{Zn}-1 ; 21$ and $20 \%$ in $\mathrm{D}+\mathrm{Zn}-2)$ in heart and liver weights as compared with diabetic control rats.

\section{Influence of dietary zinc supplementation on oxidative} stress markers in plasma, heart and liver

ROS, lipid peroxides and PC levels in plasma were significantly $(P<0.05)$ higher (by 62, 86 and 43\%, respectively) in the
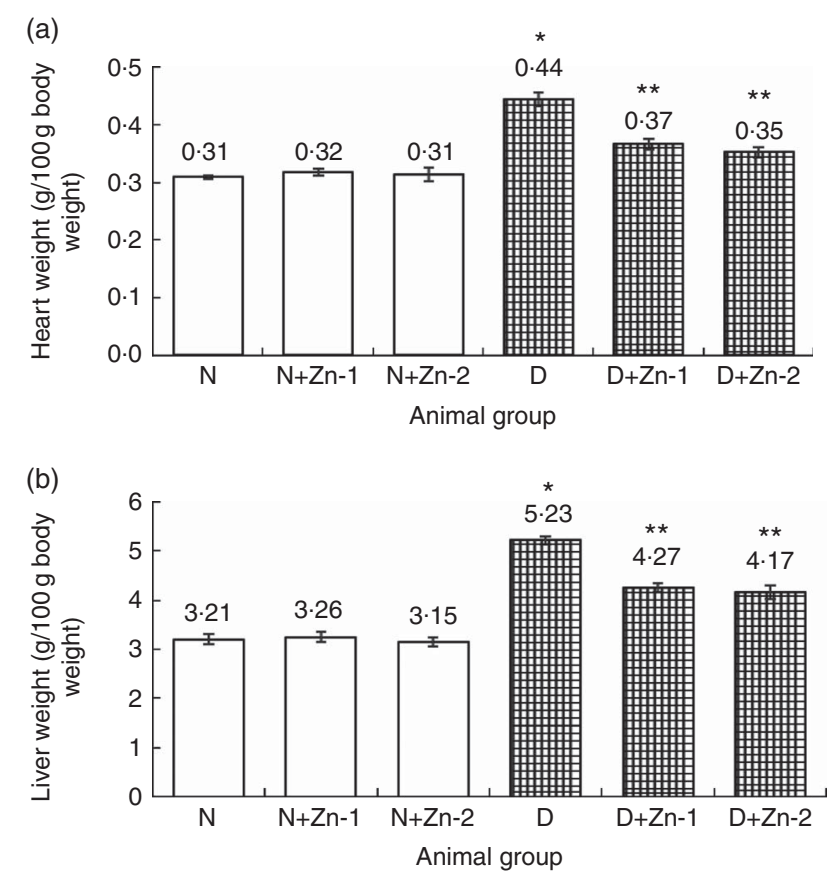

Fig. 1. Effect of zinc supplementation on (a) heart weight and (b) liver weight in diabetic rats. Values are means, with their standard errors for eight animals in each group. ${ }^{*, \star *}$ Significantly different from the normal and diabetic control groups $(P<0.05)$. N, normal control; $\mathrm{D}$, diabetic control; $\mathrm{Zn}-1$, zinc supplemented at dose $1 ; \mathrm{Zn}-2$, zinc supplemented at dose 2 . diabetic condition compared with normal control animals (Fig. 2). Dietary Zn supplementation showed noticeable lowering $(P<0.05)$ of ROS, lipid peroxides and PC content in circulation (by 18, 28 and $34 \%$ in D $+\mathrm{Zn}-1$; by 19, 30 and $26 \%$ in $\mathrm{D}+\mathrm{Zn}-2$ ). There were significant $(P<0.05)$ higher levels of ROS, lipid peroxides and PC $(65,28$ and 50\%, respectively) in the cardiac tissue of diabetic controls compared with normal control animals (Fig. 3). Dietary $\mathrm{Zn}$ supplementation resulted in a significant $(P<0.05)$ reduction in cardiac ROS, lipid peroxides and PC content (by 18, 13 and $31 \%$ in $\mathrm{D}+\mathrm{Zn}-1$; by 17,22 and $25 \%$ in $\mathrm{D}+\mathrm{Zn}-2)$. Significant increases $(P<0.05)$ in ROS, lipid peroxides and $\mathrm{PC}$ levels were also observed in hepatic tissue of diabetic rats (23, 32 and $177 \%$ increase) (Fig. 4). Dietary supplemental $\mathrm{Zn}$ significantly reduced these levels (by 14, 22 and $44 \%$ in D $+Z n-1$;
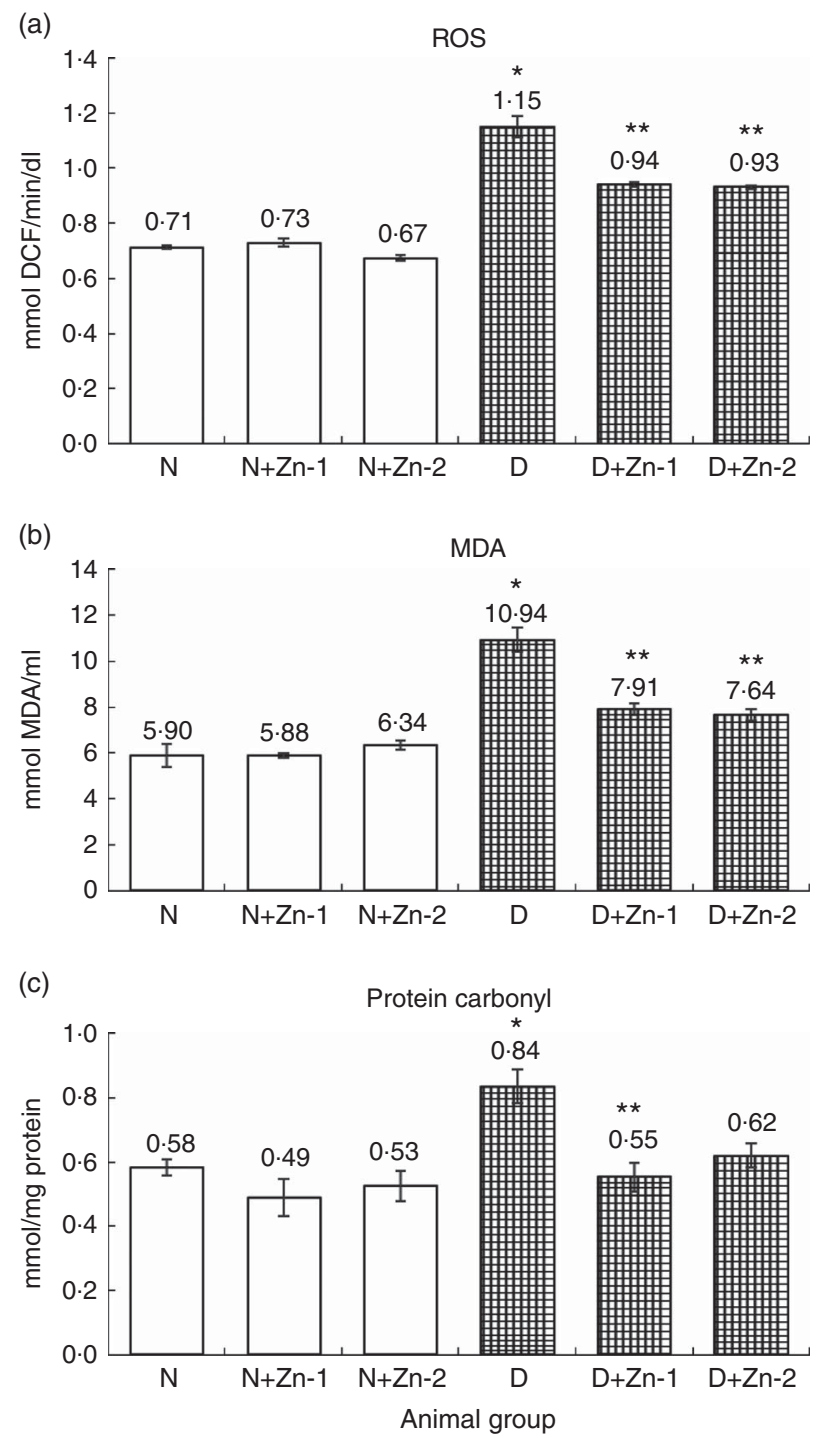

Fig. 2. Effect of zinc supplementation on oxidative stress markers: (a) reactive oxygen species (ROS) formation, (b) lipid peroxides and (c) protein oxidation levels in plasma of diabetic rats. Values are means, with their standard errors for eight animals in each group. ${ }^{*, \star \star}$ Significantly different from the normal and diabetic control groups $(P<0.05)$. DCF, 2',7'-dichlorofluorescein; $\mathrm{N}$, normal control; $\mathrm{D}$, diabetic control; Zn-1, zinc supplemented at dose 1; Zn-2, zinc supplemented at dose 2; MDA, malondialdehyde. 
Attenuation of diabetic oxidative stress by zinc

(a)
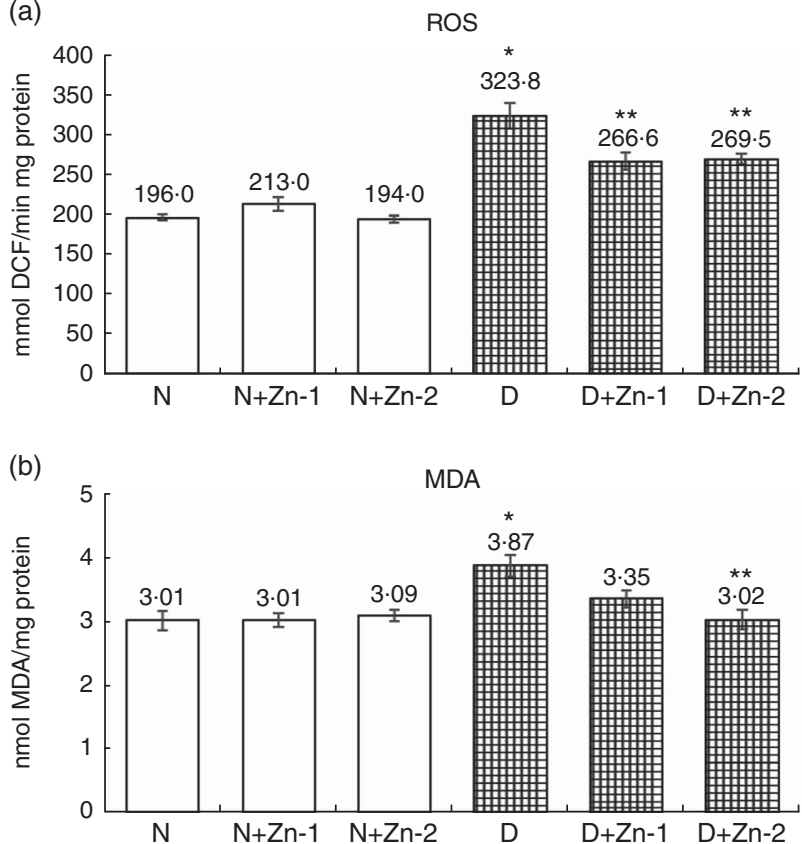

(c)

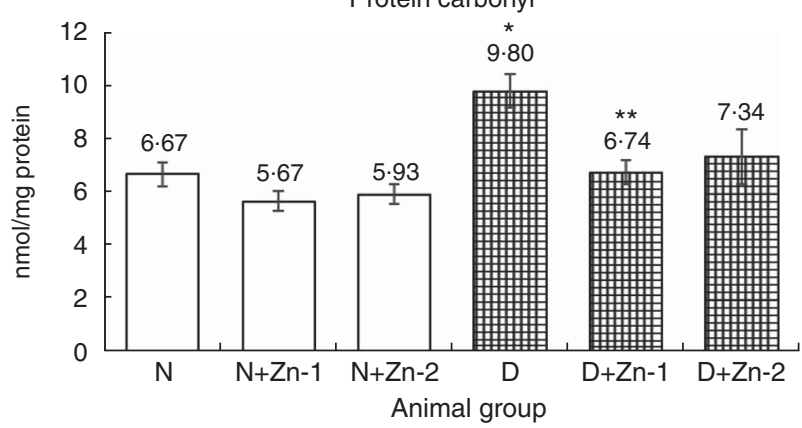

Fig. 3. Effect of zinc supplementation on oxidative stress markers: (a) reactive oxygen species (ROS) formation, (b) lipid peroxides and (c) protein oxidation levels in the heart of diabetic rats. Values are means, with their standard errors for eight animals in each group. ${ }^{*, * \star}$ Significantly different from the normal and diabetic control groups $(P<0 \cdot 05)$. DCF, 2',7'-dichlorofluorescein; $\mathrm{N}$, normal control; D, diabetic control; $\mathrm{Zn}-1$, zinc supplemented at dose 1; Zn-2, zinc supplemented at dose 2; MDA, malondialdehyde.

by 7,21 and $18 \%$ in $\mathrm{D}+\mathrm{Zn}-2)$ compared with that of diabetic control animals.

\section{Beneficial influence of dietary zinc supplementation on plasma antioxidant status}

Activities of all antioxidant enzymes (SOD, CAT, GPx, GR and GST) were significantly elevated in diabetic animals $(P<0 \cdot 05)$ concomitant with a decreased level of antioxidant molecules (ascorbic acid and GSH) compared with those of normal control animals (Table 2). Elevated activity was restricted in Zn-supplemented diabetic rats with increased level of antioxidant molecules. Among the antioxidant enzymes, the activity of SOD was increased by $23 \%(P<0.05)$ as a result of diabetes, compared with normal control rats, and the increased
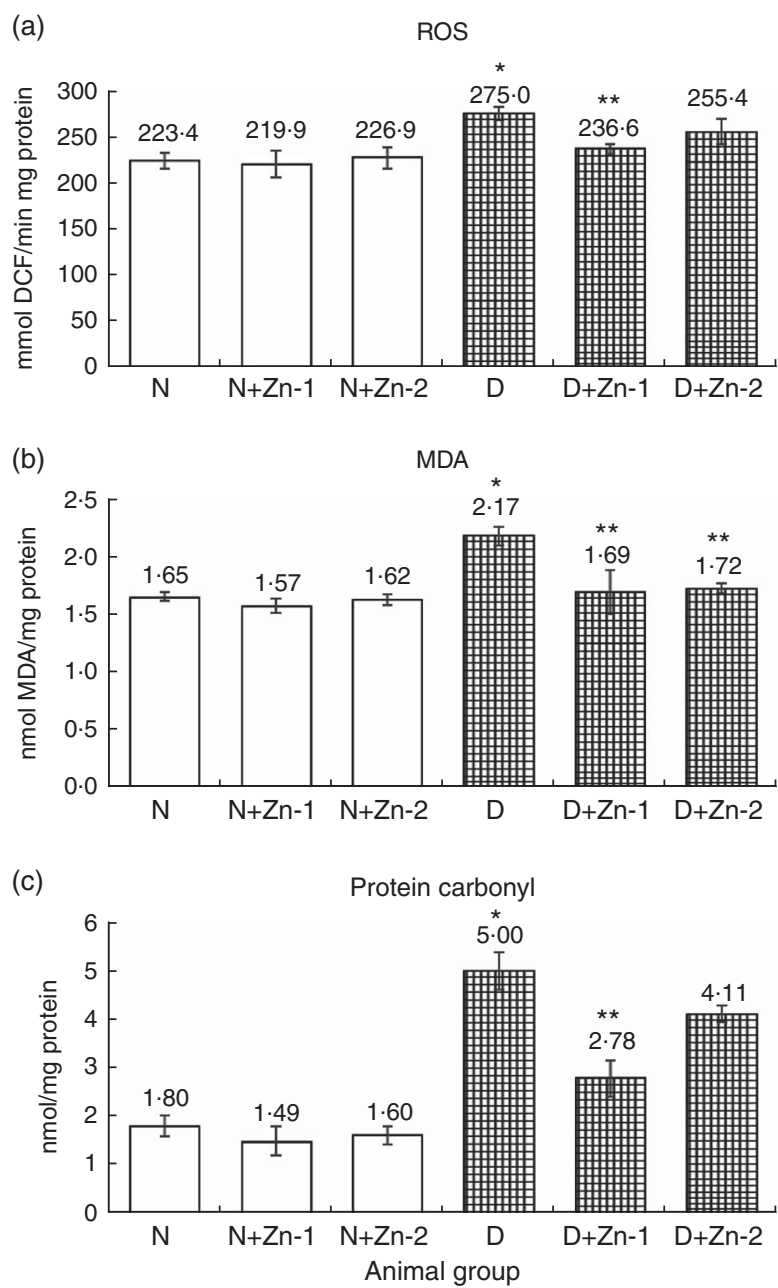

Fig. 4. Effect of zinc supplementation on oxidative stress markers: (a) reactive oxygen species (ROS) formation, (b) lipid peroxides and (c) protein oxidation levels in the liver of diabetic rats. Values are means, with their standard errors for eight animals in each group. ${ }^{* * *}$ Significantly different from the normal and diabetic control groups $(P<0.05)$. DCF, 2',7'dichlorofluorescein; $\mathrm{N}$, normal control; $\mathrm{D}$, diabetic control; $\mathrm{Zn}-1$, zinc supplemented at dose $1 ; \mathrm{Zn}-2$, zinc supplemented at dose 2; MDA, malondialdehyde.

enzyme activity was significantly $(P<0.05)$ diminished by $\mathrm{Zn}$ supplementation (by 14 and $36 \%$, respectively). CAT activity was augmented by $36 \%$ as a result of diabetes compared with normal rats, whereas $\mathrm{Zn}$ supplementation restored the enzyme activity by 49 and $66 \%$, respectively, compared with diabetic controls. The activities of GPx, GR and GST in circulation were elevated by 16,71 and $53 \%$, respectively, in the diabetic group compared with the normal control group. Dietary Zn supplementation countered the same (by 22, 8 and $32 \%$, respectively, in $\mathrm{D}+\mathrm{Zn}-1$; by 19,13 and $17 \%$, respectively, in $\mathrm{D}+\mathrm{Zn}-2$ ). Concentrations of antioxidant molecules such as ascorbic acid and GSH decreased by 38 and $41 \%(P<0.05)$, respectively, in diabetic rats compared with the normal control group. The decrease in ascorbic acid as well as GSH concentrations in diabetes was nullified by dietary interventions with $\mathrm{D}+\mathrm{Zn}-1$ (62 and 49\%, respectively) and with $\mathrm{D}+\mathrm{Zn}-2$ (61 and 68\%, 
Table 2. Influence of zinc supplementation on plasma antioxidant enzymes and antioxidant molecules in diabetic rats (Mean values with their standard errors for eight animals in each group)

\begin{tabular}{|c|c|c|c|c|c|c|c|c|c|c|c|c|c|c|}
\hline \multirow[b]{3}{*}{ Animal groups } & \multicolumn{10}{|c|}{ Antioxidant enzyme } & \multicolumn{4}{|c|}{ Antioxidant molecules } \\
\hline & \multicolumn{2}{|c|}{$\begin{array}{c}\text { SOD } \\
\text { (units/min per dl) }\end{array}$} & \multicolumn{2}{|c|}{$\begin{array}{c}\text { CAT } \\
(\mathrm{mm} / \mathrm{min} \text { per } \mathrm{dl})\end{array}$} & \multicolumn{2}{|c|}{$\begin{array}{c}\text { GPx } \\
(\mathrm{mm} / \mathrm{min} \text { per } \mathrm{dl}) \\
\end{array}$} & \multicolumn{2}{|c|}{$\begin{array}{c}\text { GR } \\
(\mathrm{mm} / \mathrm{min} \text { per dl) } \\
\end{array}$} & \multicolumn{2}{|c|}{$\begin{array}{c}\text { GST } \\
(\mathrm{mm} / \mathrm{min} \text { per } \mathrm{dl}) \\
\end{array}$} & \multicolumn{2}{|c|}{$\begin{array}{l}\text { Ascorbic acid } \\
(\mathrm{mmol} / \mathrm{l}) \\
\end{array}$} & \multicolumn{2}{|c|}{$\begin{array}{c}\text { GSH } \\
(\mathrm{mmol} / \mathrm{l})\end{array}$} \\
\hline & Mean & SEM & Mean & SEM & Mean & SEM & Mean & SEM & Mean & SEM & Mean & SEM & Mean & SEM \\
\hline Normal c & $4210 \cdot 2$ & 91.9 & $2452 \cdot 3$ & $122 \cdot 3$ & 96.5 & $2 \cdot 3$ & 3.8 & 0.03 & 4.5 & 0.2 & 0.087 & 0.01 & 0.66 & 0.05 \\
\hline Normal + Zn (dose 1) & $4087 \cdot 4$ & $92 \cdot 7$ & $2059 \cdot 1$ & $47 \cdot 4$ & $100 \cdot 1$ & $2 \cdot 7$ & $4 \cdot 4$ & 0.1 & $5 \cdot 4$ & 0.1 & 0.086 & 0.01 & 0.55 & 0.02 \\
\hline Normal + Zn (dose 2) & $4123 \cdot 8$ & $132 \cdot 6$ & $1714 \cdot 2^{\star}$ & $104 \cdot 3$ & $95 \cdot 3$ & $5 \cdot 2$ & $4 \cdot 1$ & 0.07 & $5 \cdot 5^{\star}$ & 0.3 & 0.082 & 0.01 & 0.61 & 0.02 \\
\hline Diabetic & $5171 \cdot 1^{*}$ & $96 \cdot 8$ & $3330 \cdot 0^{\star}$ & $192 \cdot 7$ & $112 \cdot 3^{*}$ & $2 \cdot 8$ & $6 \cdot 5^{*}$ & 0.2 & $6 \cdot 9^{\star}$ & 0.2 & $0.053^{*}$ & 0.002 & $0.38^{*}$ & 0.02 \\
\hline$+\mathrm{Zn}($ dose 1$)$ & $4468 \cdot 1^{\star \star}$ & $75 \cdot 1$ & $1706 \cdot 4^{\star \star}$ & 149.2 & $87 \cdot 6^{\star \star}$ & 3.5 & $6 \cdot 0$ & 0.1 & $4 \cdot 7^{\star \star}$ & 0.1 & $0.087^{\star *}$ & 0.01 & $0.57^{\star \star}$ & 0.03 \\
\hline Diabetic $+Z n$ (dose 2) & $3282 \cdot 3^{\star \star}$ & $86 \cdot 3$ & $1146 \cdot 7^{\star \star}$ & 124.4 & $91.4^{\star \star}$ & $3 \cdot 7$ & $5 \cdot 7^{* *}$ & 0.1 & $5 \cdot 7^{\star \star}$ & 0.1 & $0.086^{* *}$ & 0.01 & $0.64^{\star *}$ & 0.03 \\
\hline
\end{tabular}

SOD, superoxide dismutase; CAT, catalase; GPx, glutathione peroxidase; GR, glutathione reductase; GST, glutathione-S-transferase; .

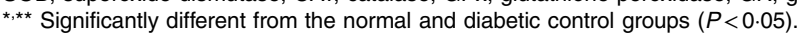

Table 3. Influence of zinc supplementation on heart antioxidant enzymes and antioxidant molecules in diabetic rats (Mean values with their standard errors for eight animals in each group)

\begin{tabular}{|c|c|c|c|c|c|c|c|c|c|c|c|c|c|c|}
\hline \multirow[b]{3}{*}{ Animal groups } & \multicolumn{10}{|c|}{ Antioxidant enzyme } & \multicolumn{4}{|c|}{ Antioxidant molecules } \\
\hline & \multicolumn{2}{|c|}{$\begin{array}{l}\text { SOD (units/min per } \\
\text { mg protein) }\end{array}$} & \multicolumn{2}{|c|}{$\begin{array}{l}\text { CAT (mm/min per } \\
\text { mg protein) }\end{array}$} & \multicolumn{2}{|c|}{$\begin{array}{l}\text { GPx }(\mu \mathrm{m} / \mathrm{min} \text { per } \\
\text { mg protein })\end{array}$} & \multicolumn{2}{|c|}{$\begin{array}{c}\mathrm{GR}(\mu \mathrm{m} / \mathrm{min} \text { per } \\
\text { mg protein })\end{array}$} & \multicolumn{2}{|c|}{$\begin{array}{l}\text { GST }(\mu \mathrm{m} / \mathrm{min} \\
\text { per mg protein) }\end{array}$} & \multicolumn{2}{|c|}{$\begin{array}{l}\text { Ascorbic acid } \\
\text { (mg/g tissue) }\end{array}$} & \multicolumn{2}{|c|}{$\begin{array}{c}\mathrm{GSH}(\mathrm{mg} / \mathrm{g} \\
\text { tissue) }\end{array}$} \\
\hline & Mean & SEM & Mean & SEM & Mean & SEM & Mean & SEM & Mean & SEM & Mean & SEM & Mean & SEM \\
\hline Normal control & $56 \cdot 7$ & $3 \cdot 1$ & $157 \cdot 0$ & $5 \cdot 9$ & $92 \cdot 7$ & 6.5 & $14 \cdot 3$ & 0.4 & $34 \cdot 3$ & 1.5 & 0.50 & 0.04 & $9 \cdot 1$ & 0.4 \\
\hline Normal + Zn (dose 1) & $69 \cdot 8$ & $4 \cdot 7$ & 152.9 & 3.0 & $98 \cdot 1$ & $4 \cdot 0$ & $16 \cdot 0$ & 0.3 & $35 \cdot 7$ & 0.7 & 0.43 & 0.03 & $9 \cdot 8$ & 0.5 \\
\hline Normal + Zn (dose 2) & $59 \cdot 7$ & $4 \cdot 8$ & $140 \cdot 6$ & $7 \cdot 1$ & $89 \cdot 8$ & $7 \cdot 1$ & $15 \cdot 8$ & 0.5 & $35 \cdot 6$ & $1 \cdot 2$ & 0.42 & 0.03 & $10 \cdot 3$ & 0.6 \\
\hline Diabetic control & $131 \cdot 1^{*}$ & $11 \cdot 7$ & $262 \cdot 8^{*}$ & $10 \cdot 1$ & $143 \cdot 0^{*}$ & $6 \cdot 3$ & $20 \cdot 7^{*}$ & 0.7 & $43 \cdot 2^{*}$ & 1.4 & $0.39^{\star}$ & 0.04 & $4.9^{*}$ & 0.2 \\
\hline Diabetic + Zn (dose 1) & $68 \cdot 8^{\star \star}$ & $2 \cdot 3$ & $226 \cdot 5^{\star \star}$ & $5 \cdot 3$ & $135 \cdot 2$ & 2.5 & $19 \cdot 5$ & 0.5 & $36 \cdot 2^{\star \star}$ & 0.9 & 0.45 & 0.02 & $7 \cdot 0^{\star *}$ & 0.4 \\
\hline Diabetic + Zn (dose 2) & $112 \cdot 8$ & $3 \cdot 2$ & $223 \cdot 8^{\star \star}$ & $7 \cdot 2$ & $112 \cdot 1^{\star *}$ & 8.9 & $17 \cdot 4^{\star \star}$ & 0.7 & 41.9 & 1.4 & $0.47^{\star}$ & 0.05 & $7 \cdot 8^{\star *}$ & 0.6 \\
\hline
\end{tabular}

SOD, superoxide dismutase; CAT, catalase; GPx, glutathione peroxidase; GR, glutathione reductase; GST, glutathione-S-transferase.

${ }^{\star, \star *}$ Significantly different from the normal and diabetic control groups $(P<0.05)$.

respectively). Zn supplementation did not alter the plasma antioxidant defence system in normal rats.

\section{Beneficial influence of dietary zinc supplementation on cardiac antioxidant status}

Activities of cardiac antioxidant enzymes were significantly higher in diabetic animals $(P<0.05)$ as compared with the normal control group (Table 3 ). SOD activity in the heart was increased by $131 \%$, and the activity of the same was significantly $(P<0.05)$ countered ( 47 and $14 \%$, respectively) in diabetic rats with $\mathrm{Zn}$ supplementation. Cardiac CAT activity was increased by about $67 \%$ in the diabetic control group compared with the normal control group, and the same was countered after Zn supplementation (14 and 15\%, respectively). The activities of GPx and GR were augmented by about 54 and $45 \%$ in the diabetic control group. The increased enzyme activity was countered by dietary $\mathrm{Zn}$ supplementation. Activities of GPx and GR were restricted by 22 and $16 \%$ in the $\mathrm{D}+\mathrm{Zn}-2$ group. Elevated GST activity was countered by $16 \%$ in the $\mathrm{D}+\mathrm{Zn}-1$ group. Concentrations of the antioxidant molecules ascorbic acid and GSH were significantly $(P<0.05)$ decreased (by 22 and $46 \%$, respectively) in diabetic rats compared with the normal control group. The decrease in ascorbic acid and GSH concentration in diabetic condition was annulled by dietary interventions with supplemental $\mathrm{Zn}$ (by 15 and $43 \%$ in $\mathrm{D}+\mathrm{Zn}-1$; by 20 and $59 \%$ in $\mathrm{D}+\mathrm{Zn}-2$ ).

\section{Beneficial influence of dietary zinc supplementation on hepatic antioxidant status}

Activities of all hepatic antioxidant enzymes were significantly altered in diabetic animals $(P<0.05)$ except for SOD and GR (Table 4). The activity of hepatic SOD in diabetic rat liver was, however, significantly $(P<0.05)$ increased (by $50 \%)$ by $\mathrm{Zn}$ supplementation $(\mathrm{D}+\mathrm{Zn}-2)$. Hepatic CAT, GPx and GST activities were diminished by 22,60 and $15 \%$, respectively, in the diabetic control group. The activities of CAT, GPx, GR and GST were increased in animals supplemented with $\mathrm{Zn}$ (by 25, 39, 25 and $33 \%$, respectively, in $\mathrm{D}+\mathrm{Zn}-1$ and by $16,40,28$ and $12 \%$, respectively, in $\mathrm{D}+\mathrm{Zn}-2$ ). Concentrations of the antioxidant molecules ascorbic acid and GSH in diabetic rats decreased by 32 and $15 \%(P<0.05)$, respectively, compared with the normal control group. This decrease was negated by dietary Zn supplementation (by 32 and $23 \%$ in $\mathrm{D}+\mathrm{Zn}-1$ and by 27 and $21 \%$, respectively, in $\mathrm{D}+\mathrm{Zn}-2$ ).

\section{Influence of dietary zinc supplementation on cardiac marker enzymes}

Plasma CK-MB activity was elevated by 2-fold in diabetic condition compared with the normal control group (Fig. 5). 
Table 4. Influence of zinc supplementation on liver antioxidant enzymes and antioxidant molecules in diabetic rats (Mean values with their standard errors for eight animals in each group)

\begin{tabular}{|c|c|c|c|c|c|c|c|c|c|c|c|c|c|c|}
\hline \multirow[b]{3}{*}{ Animal groups } & \multicolumn{10}{|c|}{ Antioxidant enzyme } & \multicolumn{4}{|c|}{ Antioxidant molecules } \\
\hline & \multicolumn{2}{|c|}{$\begin{array}{l}\text { SOD (units/min } \\
\text { per mg protein) }\end{array}$} & \multicolumn{2}{|c|}{$\begin{array}{l}\text { CAT (mm/min per } \\
\text { mg protein) }\end{array}$} & \multicolumn{2}{|c|}{$\begin{array}{l}\text { GPx }(\mu \mathrm{m} / \mathrm{min} \text { per } \\
\text { mg protein })\end{array}$} & \multicolumn{2}{|c|}{$\begin{array}{l}\mathrm{GR}(\mu \mathrm{m} / \mathrm{min} \text { per } \\
\text { mg protein) }\end{array}$} & \multicolumn{2}{|c|}{$\begin{array}{l}\text { GST }(\mathrm{mm} / \mathrm{min} \text { per } \\
\text { mg protein) }\end{array}$} & \multicolumn{2}{|c|}{$\begin{array}{l}\text { Ascorbic acid } \\
\text { (mg/g tissue) }\end{array}$} & \multicolumn{2}{|c|}{$\begin{array}{l}\text { GSH }(\mathrm{mg} / \mathrm{g} \\
\text { tissue) }\end{array}$} \\
\hline & Mean & SEM & Mean & SEM & Mean & SEM & Mean & SEM & Mean & SEM & Mean & SEM & Mean & SEM \\
\hline Normal control & 93.6 & $2 \cdot 0$ & $252 \cdot 4$ & $10 \cdot 9$ & $798 \cdot 1$ & $6 \cdot 2$ & $56 \cdot 3$ & $1 \cdot 2$ & $384 \cdot 0$ & $6 \cdot 4$ & $242 \cdot 3$ & $12 \cdot 6$ & $15 \cdot 1$ & 0.6 \\
\hline Normal + Zn (dose 1) & $101 \cdot 6$ & $2 \cdot 4$ & $227 \cdot 7$ & $6 \cdot 7$ & $814 \cdot 3$ & 20.9 & $57 \cdot 7$ & 1.0 & $394 \cdot 1$ & $11 \cdot 8$ & $223 \cdot 2$ & $8 \cdot 7$ & $14 \cdot 7$ & 0.9 \\
\hline Normal + Zn (dose 2) & 99.9 & $5 \cdot 8$ & $235 \cdot 7$ & $12 \cdot 9$ & 874.3 & $6 \cdot 2$ & $68 \cdot 3$ & $2 \cdot 8$ & $411 \cdot 1$ & $7 \cdot 7$ & $258 \cdot 0$ & $13 \cdot 2$ & $14 \cdot 2$ & $1 \cdot 0$ \\
\hline Diabetic control & $100 \cdot 6$ & $4 \cdot 3$ & $195 \cdot 7^{*}$ & 11.9 & $318 \cdot 0^{*}$ & $7 \cdot 1$ & $56 \cdot 5$ & 2.9 & $325 \cdot 3$ & 13.5 & $164 \cdot 1^{*}$ & $6 \cdot 9$ & $12 \cdot 9^{\star}$ & 0.4 \\
\hline Diabetic $+Z n$ (dose 1) & $88 \cdot 3$ & $6 \cdot 7$ & $245 \cdot 4^{\star \star}$ & $7 \cdot 4$ & $442 \cdot 4^{\star \star}$ & $25 \cdot 2$ & $70 \cdot 4^{\star *}$ & $2 \cdot 1$ & $434 \cdot 1^{\star *}$ & $26 \cdot 2$ & $216 \cdot 7^{\star \star}$ & $3 \cdot 1$ & $15 \cdot 9^{\star \star}$ & 0.5 \\
\hline Diabetic $+Z n$ (dose 2) & $150 \cdot 1^{\star *}$ & $12 \cdot 8$ & $226 \cdot 7$ & $13 \cdot 3$ & $443 \cdot 6^{\star \star}$ & $16 \cdot 4$ & $72 \cdot 5^{\star \star}$ & $1 \cdot 8$ & $365 \cdot 7$ & $10 \cdot 4$ & $209 \cdot 2^{\star \star}$ & $1 \cdot 1$ & $15 \cdot 6^{\star \star}$ & 0.6 \\
\hline
\end{tabular}

SOD, superoxide dismutase; CAT, catalase; GPx, glutathione peroxidase; GR, glutathione reductase; GST, glutathione-S-transferase.

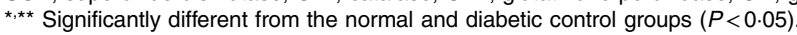

(a)

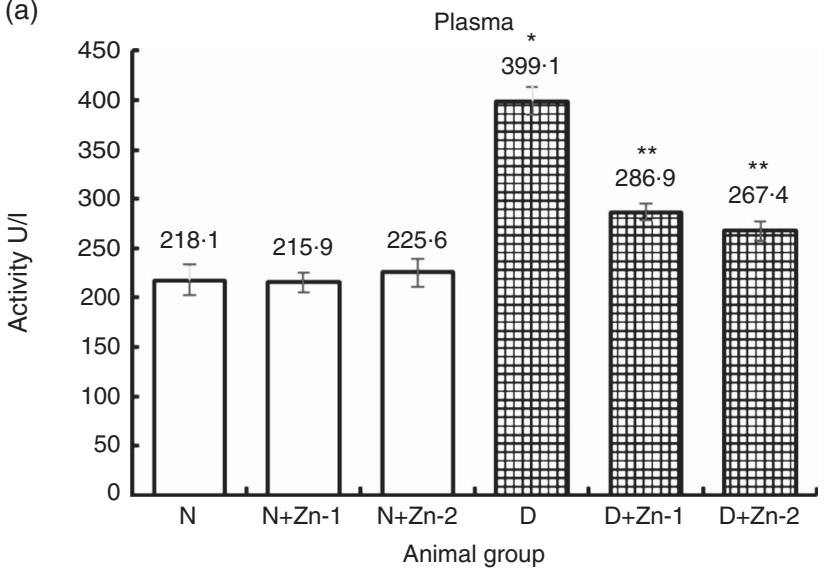

(b)

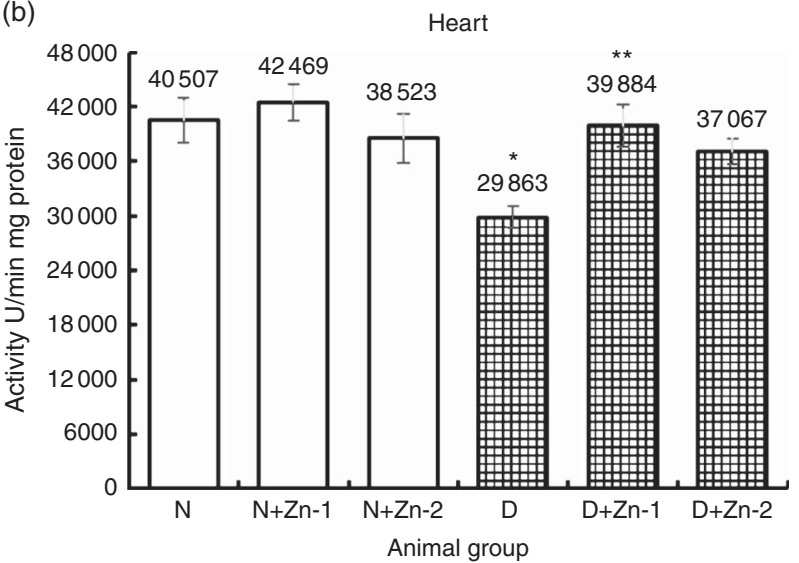

Fig. 5. Influence of zinc supplementation on cardiac marker enzyme creatine kinase in (a) plasma and (b) heart tissue of diabetic rats. Values are means, with their standard errors for eight animals in each group. ${ }^{*, * *}$ Significantly different from the normal and diabetic control groups $(P<0.05)$. N, normal control; D, diabetic control; $Z n-1$, zinc supplemented at dose $1 ; \mathrm{Zn}-2$, zinc supplemented at dose 2 .

Dietary Zn supplementation in diabetic animals reduced the quantum of increase in this enzyme activity by 28 and $33 \%$, respectively $(P<0 \cdot 05)$. Dietary supplemental $\mathrm{Zn}$ intervention countered the decrease in CK-MB activity in heart tissue of diabetic rats by 34 and $24 \%$ (at dose- 1 and dose-2, respectively), which was reduced by $26 \%$ in diabetes.

\section{Influence of dietary zinc supplementation on hepatic marker enzymes}

Activities of hepatic marker enzymes including ALP, ALT and AST in plasma were increased in the circulation of diabetic rats by 51,84 and $37 \%$, respectively $(P<0.05)$ (Fig. 6). Increase in the activities of aminotransferases was significantly countered in rats treated with dietary $\mathrm{Zn}$ supplementation. Dietary interventions with $\mathrm{Zn}-1$ prevented the elevation in these enzyme activities by 23, 23 and 31\%, respectively, whereas $\mathrm{Zn}-2$ countered the same by 16, 28 and $29 \%$, correspondingly $(P<0.05)$.

\section{Beneficial influence of dietary zinc supplementation on plasma lipid profile}

Hyperlipidaemia as an outcome of diabetic disorder significantly $(P<0.05)$ exhibited an increase in plasma cholesterol $(72 \%)$ concomitant with raised LDL-associated cholesterol (166\%) and decreased HDL-associated cholesterol (48\%), increase in TAG (330\%) and phospholipids (67\%), respectively, compared with normal control animals (Table 5). Zn-supplemented diets significantly $(P<0.05)$ ameliorated this condition. There was a 36 and $56 \%$ decrease in cholesterol and LDL-associated cholesterol concomitant with elevation in HDL-associated cholesterol by $69 \%$ in the $\mathrm{Zn}$-supplementation ( $\mathrm{Zn}$-1) groups, whereas in the groups fed $\mathrm{Zn}-2$ the decrease in cholesterol was 34, 50 and 50\%. Elevated TAG and phospholipid levels were also countered by Zn-1 (36 and $16 \%$ ) and $\mathrm{Zn}-2$ ( 42 and 30\%, respectively). Concomitant with the favourable moderation of raised cholesterol and phospholipid concentrations in diabetes, dietary intervention with $\mathrm{Zn}$ supplementation also countered the cholesterol:phospholipid ratio (Fig. 7(a)). There was also a favourable effect on the calculated atherogenicity index (Fig. 7(b)) with pronounced counteraction by 76 and $68 \%$, respectively (Table 5).

\section{Beneficial influence of dietary zinc supplementation on heart lipid profile}

Heart muscle cholesterol and TAG contents were increased by 61 and $22 \%$, respectively, compared with normal control rats (Table 6). Diabetic rats treated with supplemental Zn-containing diets showed significant recovery (32 and 20\% in $\mathrm{D}+\mathrm{Zn}-1$ rat and 11 and $17 \%$ in $\mathrm{D}+\mathrm{Zn}-2$, respectively) in 
(a)

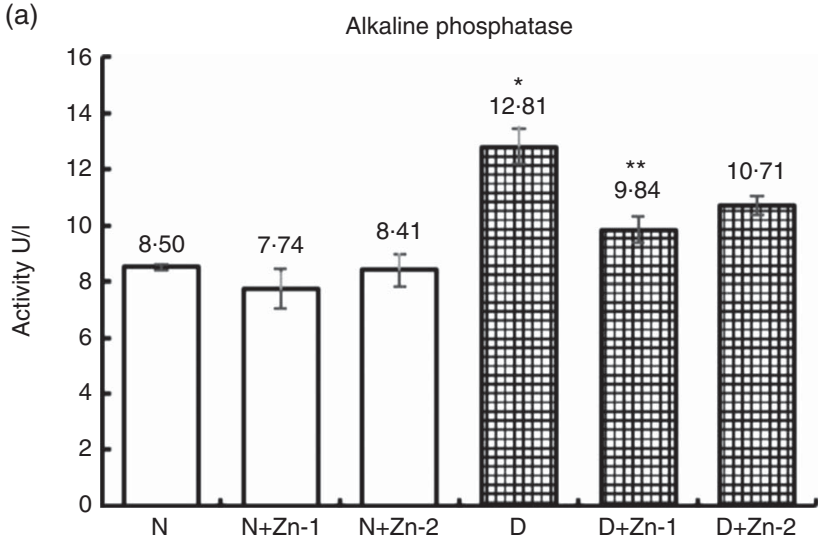

(b)
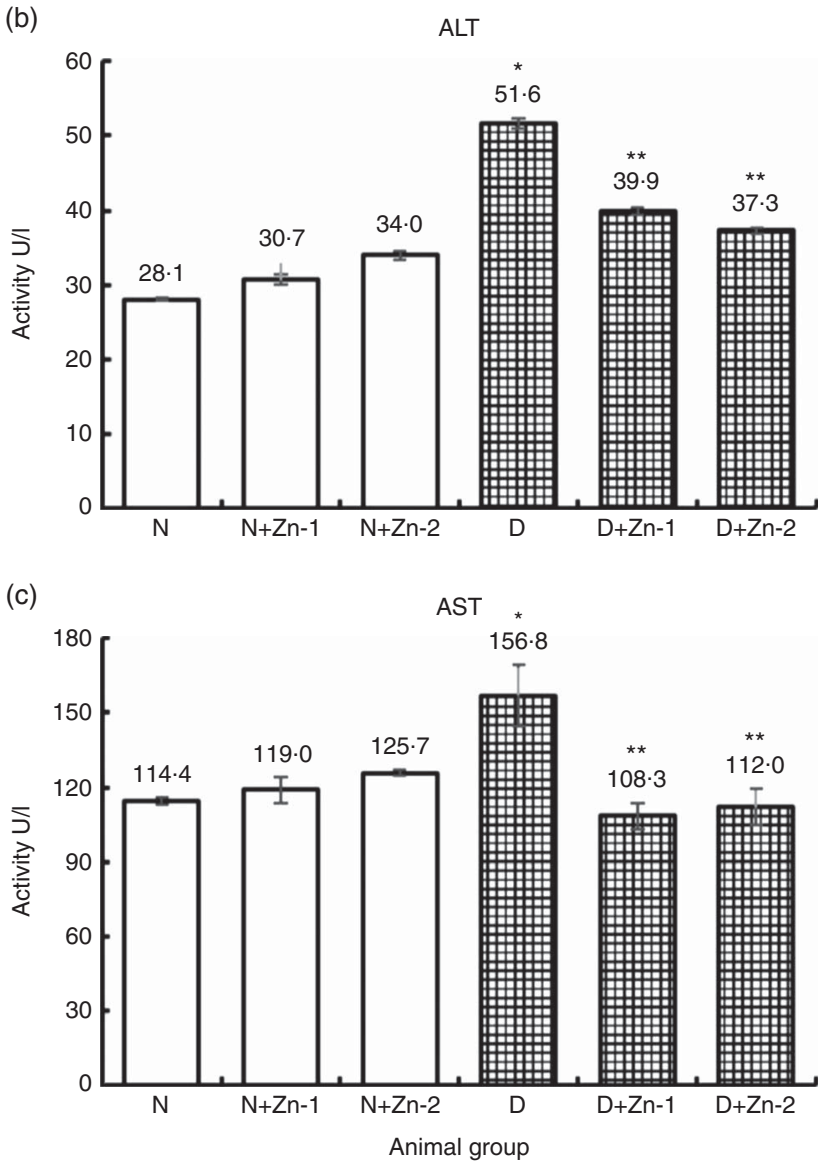

Fig. 6. Influence of zinc supplementation on liver necrosis biomarkers: (a) alkaline phosphatase, (b) alanine aminotransferase (ALT) and (c) aspartate aminotransferase (AST) in plasma of diabetic rats. Values are means, with their standard errors for eight animals in each group. *,** Significantly different from the normal and diabetic control groups $(P<0.05)$. N, normal control; D, diabetic control; $\mathrm{Zn}-1$, zinc supplemented at dose $1 ;$ Zn-2, zinc supplemented at dose 2.

cholesterol and TAG levels as compared with the diabetic rats on control diet $(P<0 \cdot 05)$. Cardiac phospholipid levels were significantly $(P<0.05)$ decreased $(34 \%)$ under diabetic conditions when compared with normal rats, and were restored in the diabetic groups treated with dietary Zn (dose-2) supplementation by $21 \%$. The cholesterol:phospholipid ratio was increased by

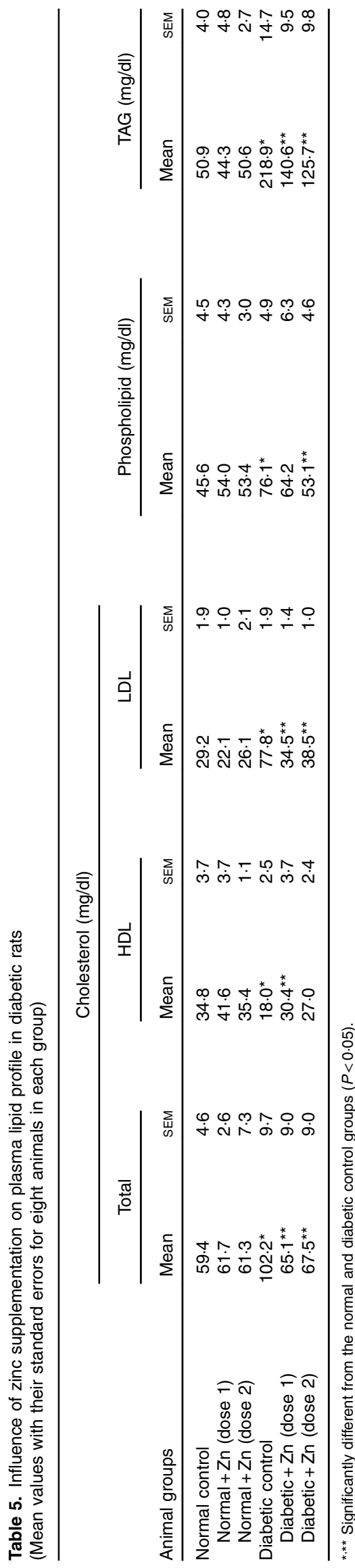



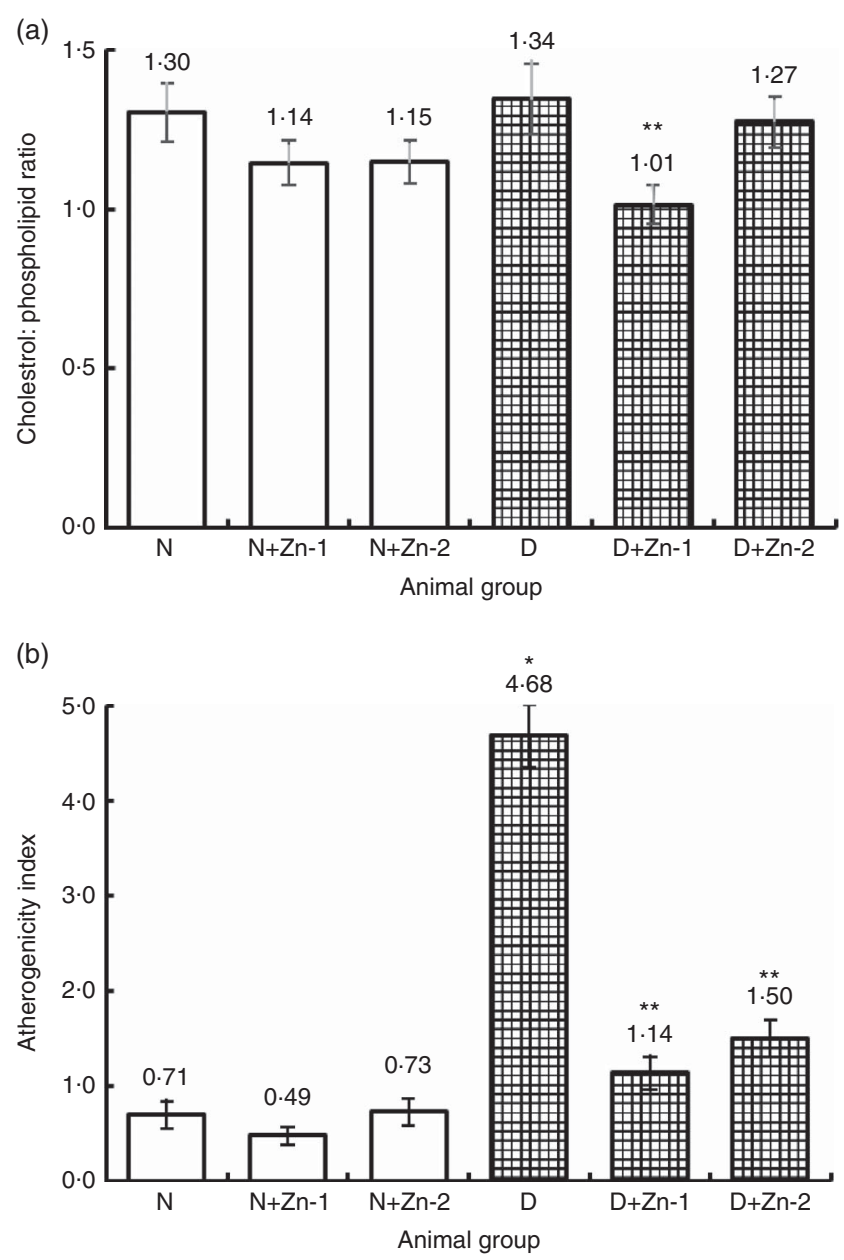

Fig. 7. Effect of zinc supplementation on plasma (a) cholesterol:phospholipid ratio and (b) atherogenicity index in diabetic rats. Values are means, with their standard errors for eight animals in each group. ${ }^{*, *}$ Significantly different from the normal and diabetic control groups $(P<0.05)$. $\mathrm{N}$, normal control; $\mathrm{D}$, diabetic control; Zn-1, zinc supplemented at dose $1 ; \mathrm{Zn}-2$, zinc supplemented at dose 2.

diabetes (137\%), whereas feeding of supplemental Zn effectively reduced the same (37 and $29 \%$, respectively) $(P<0 \cdot 05)$.

Effect of Zn supplementation on fatty acid composition of cardiac lipids was analysed in groups of diabetic rats (Table 7). Diabetic rats demonstrated a protuberant decrease in MUFA and PUFA - such as oleic acid (18:1) and linoleic acid (18:2) - in cardiac tissue (32 and $15 \%$, respectively) as compared with normal controls. There was a significant increase in oleic acid (18:1), linoleic acid $(18: 2)$, arachidonic acid (20:4) and DHA (22:6) accompanied by a decrease in myristic acid (14:0), palmitic acid (16:0) and stearic acid (18:0) in diabetic rats as a result of $\mathrm{Zn}$ supplementation. The PUFA: SFA ratio was thus significantly decreased in diabetic condition (approximately 23\%) as compared with normal control animals. Zn supplementation of diabetic animals resulted in an improvement in the PUFA:SFA ratio (about 36 and 29\%, respectively).

\section{Influence of dietary zinc supplementation on liver lipid profile}

The influence of dietary $\mathrm{Zn}$ supplementation on lipid profile in hepatic tissue of normal and diabetic animals is indicated in Table 8. Diabetic liver exhibited significantly $(P<0.05)$ elevated levels of all lipid components, among which TAG increased by about $73 \%$ accompanied with $32 \%$ elevation in cholesterol and $19 \%$ increase in phospholipids as compared with the normal control group. This increase in hepatic TAG and cholesterol was countered by $\mathrm{Zn}$ supplementation to a marked extent (19 and $21 \%$, respectively, by $\mathrm{D}+\mathrm{Zn}-1$ and 42 and $25 \%$, respectively, by $\mathrm{D}+\mathrm{Zn}-2$ ). The cholesterol:phospholipid ratio was also beneficially amended in the Zn-supplemented group $\mathrm{D}+\mathrm{Zn}-2$.

\section{Influence of dietary zinc supplementation on the mRNA expressions of fibrosis and pro-apoptotic markers in cardiac and hepatic tissue of diabetic rats}

The favourable effect of $\mathrm{Zn}$ supplementation was also evident by the countering of diabetes-induced fibrotic, apoptotic and oxidative gene overexpression at the organ level. The mRNA transcripts of fibrosis (fibronectin and collagen IV) and pro-apoptotic (BCL2 associated X protein; Bax) markers in cardiac tissue (Fig. 8) were augmented in diabetic condition by $>3.5$ and 1.9-fold, respectively, compared with normal animals. Overexpression of fibronectin and type IV collagen in the cardiac tissue of diabetic animals was markedly attenuated by supplemental $\mathrm{Zn}(54 \%$ in $\mathrm{D}+\mathrm{Zn}-1$ and 58 and $52 \%$ in $\mathrm{D}+\mathrm{Zn}-2$, respectively). Hyperglycaemia-induced overexpression of Bax and lowered mRNA expression of B-cell lymphoma 2 (Bcl-2) were reversed by $\mathrm{Zn}$ treatment in a dose-dependent manner. $\mathrm{Zn}$ treatment could considerably suppress the elevation of Bax and up-regulate the expression of $\mathrm{Bcl}-2$, contributing to the suppression of the augmented Bax:Bcl-2 ratio in myocardial tissue.

Similarly, mRNA transcripts of fibrosis (fibronectin and collagen IV) and pro-apoptotic (Bax) markers in the hepatic tissue were augmented in diabetic condition by $>2$-fold compared with normal animals (Fig. 9). Overexpression of fibronectin and type IV collagen in the hepatic tissue of diabetic animals was markedly attenuated by supplemental $\mathrm{Zn}(P<0 \cdot 5)$. Hyperglycaemia-induced overexpression of Bax mRNA and lowered mRNA expression of $\mathrm{Bcl}-2$ were reversed by $\mathrm{Zn}$ treatment in a dose-dependent manner. Zn treatment could considerably down-regulate the expression of Bax and up-regulate the expression of $\mathrm{Bcl}-2$, contributing to the suppression of augmented Bax:Bcl-2 ratio in the liver.

To better understand the molecular mechanism underlying the alleviation of oxidative stress by $\mathrm{Zn}$ supplementation in diabetes, cardiac tissue expression of 4-HNE protein was assessed (Fig. 10). In diabetes, protein expression of 4-HNE in heart tissue was augmented by $>1 \cdot 17$-fold as compared with the normal control group. Diabetic rats treated with supplemental $\mathrm{Zn}$ noticeably countered the same $(P<0.05)$ (by $62 \%$ in $\mathrm{D}+\mathrm{Zn}-1$ and by $18 \%$ in $\mathrm{D}+\mathrm{Zn}-2$ group).

\section{Beneficial influence of zinc supplementation on histopathology of heart and liver tissue in diabetic rats}

The effects of $\mathrm{Zn}$ supplementation on diabetic cardiomyopathy were examined with respect to morphological changes and development of fibrosis. Morphological reflection by $\mathrm{H} \& \mathrm{E}$ 
Table 6. Influence of zinc supplementation on heart lipid profile in diabetic rats

(Mean values with their standard errors for eight animals in each group)

\begin{tabular}{|c|c|c|c|c|c|c|c|c|}
\hline \multirow[b]{2}{*}{ Animal groups } & \multicolumn{2}{|c|}{ Cholesterol (mg/g tissue) } & \multicolumn{2}{|c|}{ Phospholipid (mg/g tissue) } & \multicolumn{2}{|c|}{ TAG (mg/g tissue) } & \multicolumn{2}{|c|}{ Cholesterol:phospholipids } \\
\hline & Mean & SEM & Mean & SEM & Mean & SEM & Mean & SEM \\
\hline Normal control & 3.9 & 0.4 & $25 \cdot 7$ & $2 \cdot 0$ & $41 \cdot 1$ & 1.0 & 0.16 & 0.02 \\
\hline Normal + Zn (dose 1) & 3.4 & 0.3 & $23 \cdot 7$ & 1.7 & $34 \cdot 7$ & $1 \cdot 2$ & 0.14 & 0.008 \\
\hline Normal + Zn (dose 2) & $3 \cdot 7$ & 0.6 & $25 \cdot 5$ & $1 \cdot 8$ & $40 \cdot 3$ & 2.5 & 0.15 & 0.01 \\
\hline Diabetic control & $6 \cdot 3^{*}$ & 0.4 & $16 \cdot 9^{*}$ & 0.8 & $50 \cdot 0$ & $2 \cdot 4$ & $0.38^{*}$ & 0.007 \\
\hline Diabetic + Zn (dose 1) & $4 \cdot 3^{\star \star}$ & 0.6 & $17 \cdot 8$ & 0.8 & $39 \cdot 8^{\star \star}$ & $3 \cdot 6$ & $0.24^{\star \star}$ & 0.02 \\
\hline Diabetic + Zn (dose 2) & $5 \cdot 6$ & 0.3 & $20 \cdot 5$ & $2 \cdot 1$ & 41.5 & 0.9 & $0.27^{\star \star}$ & 0.01 \\
\hline
\end{tabular}

${ }^{* * \star *}$ Significantly different from the normal and diabetic control groups $(P<0.05)$.

Table 7. Influence of zinc supplementation on heart fatty acid composition ( $\mathrm{mol} / 100 \mathrm{~mol})$ in diabetic rats (Values are means with their standard errors for eight animals in each group)

\begin{tabular}{|c|c|c|c|c|c|c|c|c|c|c|c|c|}
\hline \multirow[b]{2}{*}{ Fatty acids } & \multicolumn{2}{|c|}{ Normal control } & \multicolumn{2}{|c|}{ Normal + Zn (dose 1) } & \multicolumn{2}{|c|}{ Normal + Zn (dose 2) } & \multicolumn{2}{|c|}{ Diabetic control } & \multicolumn{2}{|c|}{ Diabetic $+Z n$ (dose 1) } & \multicolumn{2}{|c|}{ Diabetic $+\mathrm{Zn}$ (dose 2) } \\
\hline & Mean & SEM & Mean & SEM & Mean & SEM & Mean & SEM & Mean & SEM & Mean & SEM \\
\hline $14: 0$ & 0.52 & 0.06 & 0.49 & 0.07 & 0.50 & 0.03 & 0.61 & 0.07 & 0.52 & 0.06 & 0.52 & 0.07 \\
\hline $14: 1$ & 0.87 & 0.08 & 1.09 & 0.1 & 0.89 & 0.06 & 0.71 & 0.06 & 0.93 & 0.07 & 0.87 & 0.06 \\
\hline $16: 0$ & $12 \cdot 2$ & 0.2 & $11 \cdot 3$ & 0.2 & $12 \cdot 6$ & 0.3 & $13 \cdot 1$ & 0.2 & 11.4 & 0.1 & $10 \cdot 1$ & 0.1 \\
\hline $16: 1$ & 0.75 & 0.02 & 0.58 & 0.01 & 0.85 & 0.04 & 0.78 & 0.02 & 1.02 & 0.04 & 0.93 & 0.07 \\
\hline $18: 0$ & $17 \cdot 5$ & $1 \cdot 0$ & $19 \cdot 0$ & 0.3 & $18 \cdot 9$ & 0.2 & 23.5 & 0.3 & $18 \cdot 1$ & 0.2 & $20 \cdot 9$ & 0.3 \\
\hline $18: 1$ & 12.02 & 0.8 & $8 \cdot 7$ & 0.07 & $10 \cdot 9$ & 0.8 & $8 \cdot 2$ & 0.1 & $9 \cdot 9$ & 0.3 & 8.9 & 0.6 \\
\hline $18: 2$ & $21 \cdot 7$ & 0.6 & $18 \cdot 9$ & 0.3 & $19 \cdot 7$ & 0.3 & $18 \cdot 5$ & 0.1 & $19 \cdot 5$ & 0.5 & $19 \cdot 1$ & 0.7 \\
\hline $18: 3$ & 0.50 & 0.09 & 0.46 & 0.03 & 0.44 & 0.02 & 0.45 & 0.09 & 0.48 & 0.07 & 0.41 & 0.01 \\
\hline $20: 1$ & 0.24 & 0.008 & 0.34 & 0.02 & 0.28 & 0.01 & 0.53 & 0.03 & 0.57 & 0.01 & 0.64 & 0.07 \\
\hline $20: 2$ & 0.57 & 0.06 & 0.88 & 0.05 & 0.74 & 0.09 & 0.98 & 0.11 & $1 \cdot 22$ & 0.16 & 1.04 & 0.28 \\
\hline $20: 3$ & $1 \cdot 21$ & 0.5 & 1.73 & 0.3 & 0.52 & 0.03 & 0.59 & 0.04 & 0.57 & 0.08 & 0.64 & 0.02 \\
\hline $20: 4$ & $20 \cdot 8$ & 0.4 & $24 \cdot 2$ & 0.5 & $22 \cdot 8$ & 0.3 & 20.4 & 0.8 & 23.0 & 0.3 & $22 \cdot 3$ & 0.5 \\
\hline $20: 5$ & $2 \cdot 10$ & 0.02 & $2 \cdot 22$ & 0.04 & $2 \cdot 01$ & 0.08 & 2.07 & 0.08 & $2 \cdot 33$ & 0.05 & $2 \cdot 14$ & 0.09 \\
\hline $22: 1$ & $1 \cdot 31$ & 0.3 & $1 \cdot 11$ & 0.04 & 1.07 & 0.06 & 0.44 & 0.01 & 0.48 & 0.03 & 0.65 & 0.07 \\
\hline $22: 5$ & 0.80 & 0.01 & 1.42 & 0.01 & 0.82 & 0.009 & 0.60 & 0.004 & 0.80 & 0.006 & 0.71 & 0.08 \\
\hline $22: 6$ & $5 \cdot 80$ & 0.11 & $6 \cdot 51$ & 0.23 & $5 \cdot 75$ & 0.30 & $7 \cdot 28$ & 0.49 & 7.97 & 0.25 & $9 \cdot 12$ & 0.63 \\
\hline $24: 1$ & 1.19 & 0.03 & $1 \cdot 11$ & 0.06 & 1.36 & 0.05 & $1 \cdot 17$ & 0.04 & $1 \cdot 21$ & 0.06 & $1 \cdot 12$ & 0.06 \\
\hline PUFA & 53.48 & & $56 \cdot 32$ & & 52.78 & & 50.87 & & 55.87 & & 55.46 & \\
\hline SFA & $30 \cdot 22$ & & $30 \cdot 79$ & & 32 & & $37 \cdot 21$ & & 30.02 & & 31.52 & \\
\hline PUFA:SFA & 1.77 & & 1.83 & & 1.65 & & $1 \cdot 37$ & & 1.86 & & $1 \cdot 76$ & \\
\hline
\end{tabular}

Table 8. Influence of zinc supplementation on liver lipid profile in diabetic rats

(Values are means with their standard errors for eight animals in each group)

\begin{tabular}{|c|c|c|c|c|c|c|c|c|}
\hline \multirow[b]{2}{*}{ Animal groups } & \multicolumn{2}{|c|}{ Cholesterol (mg/g tissue) } & \multicolumn{2}{|c|}{ Phospholipid (mg/g tissue) } & \multicolumn{2}{|c|}{ TAG (mg/g tissue) } & \multicolumn{2}{|c|}{ Cholesterol:phospholipids } \\
\hline & Mean & SEM & Mean & SEM & Mean & SEM & Mean & SEM \\
\hline Normal control & 8.9 & 0.4 & $65 \cdot 6$ & $6 \cdot 2$ & $16 \cdot 3$ & 1.4 & 0.14 & 0.01 \\
\hline Normal + Zn (dose 1) & $8 \cdot 3$ & 0.6 & $67 \cdot 7$ & 4.9 & 14.9 & $2 \cdot 3$ & 0.13 & 0.01 \\
\hline Normal + Zn (dose 2) & $8 \cdot 7$ & 0.6 & $74 \cdot 3$ & 5.9 & $16 \cdot 7$ & 0.9 & 0.12 & 0.02 \\
\hline Diabetic control & $11 \cdot 7^{*}$ & 0.4 & $78 \cdot 1$ & 3.4 & $28 \cdot 2^{*}$ & 0.6 & 0.15 & 0.005 \\
\hline Diabetic + Zn (dose 1) & $9 \cdot 2^{\star \star}$ & 0.6 & $71 \cdot 3$ & $3 \cdot 3$ & $22 \cdot 9^{\star \star}$ & 1.5 & 0.13 & 0.008 \\
\hline Diabetic + Zn (dose 2) & $8 \cdot 8^{\star \star}$ & 0.7 & $84 \cdot 7$ & 5.0 & $16 \cdot 5^{\star \star}$ & $1 \cdot 1$ & $0 \cdot 10^{\star \star}$ & 0.02 \\
\hline
\end{tabular}

${ }^{\star, \star \star}$ Significantly different from the normal and diabetic control groups $(P<0.05)$.

staining under light microscopy (Fig. 11) indicated that diabetes prompted a significantly disorganised cardiac architecture due of extensive interstitial fibrosis with mononuclear inflammatory infiltration, myofibrillar loss and cytoplasmic vacuolisation. The beneficial alteration in myocardial architecture was observed in improvement of these degenerative changes of the myocardium as the nuclei appeared nearly equal in size with uniform shape in rats supplemented with Zn (Fig. 11). As an index of the cardiac fibrotic effect of diabetes, PAS staining and Masson's trichrome staining were used for identification of glycogen and collagen, respectively. Significantly increased pink positive materials (purple plaques) were an indication of glycogen deposition in the hearts of diabetic rat, and this was almost abated in the Zn-supplemented groups (Fig. 11). Accumulation 
(a)

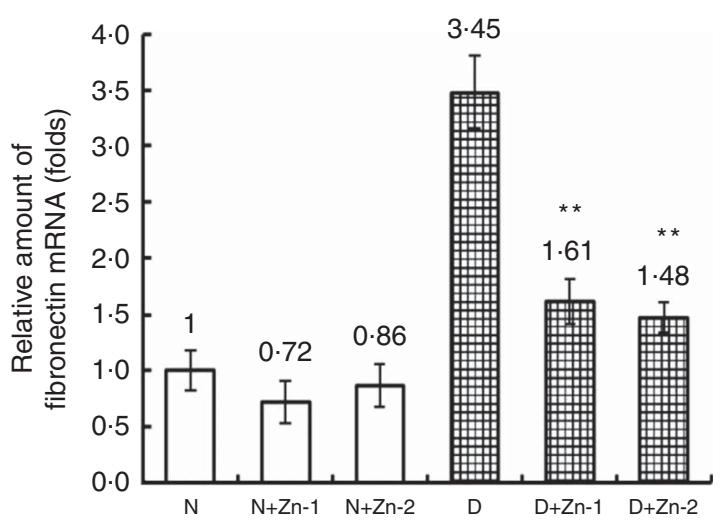

(b)

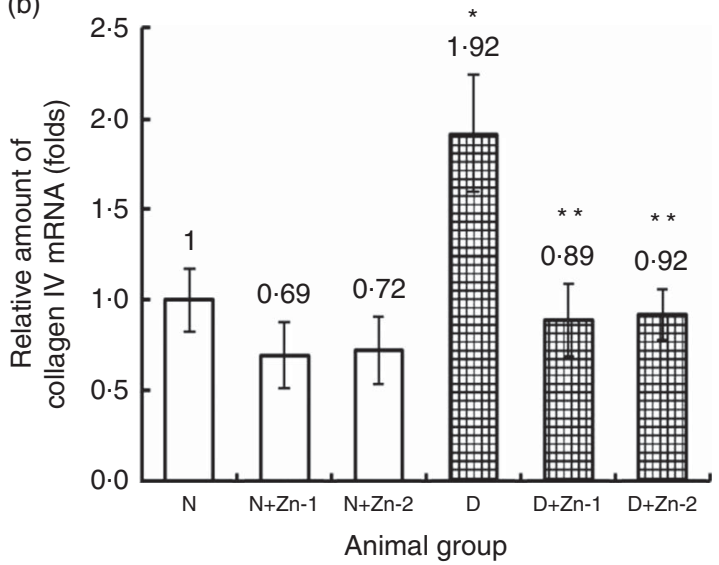

(c)

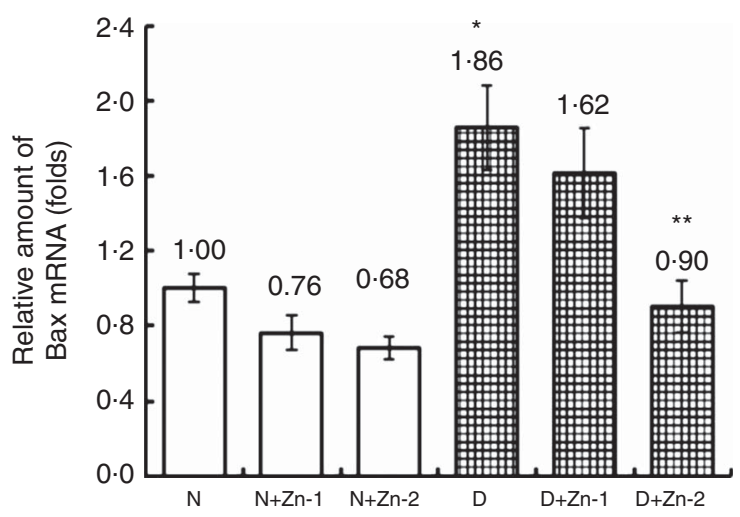

(d)

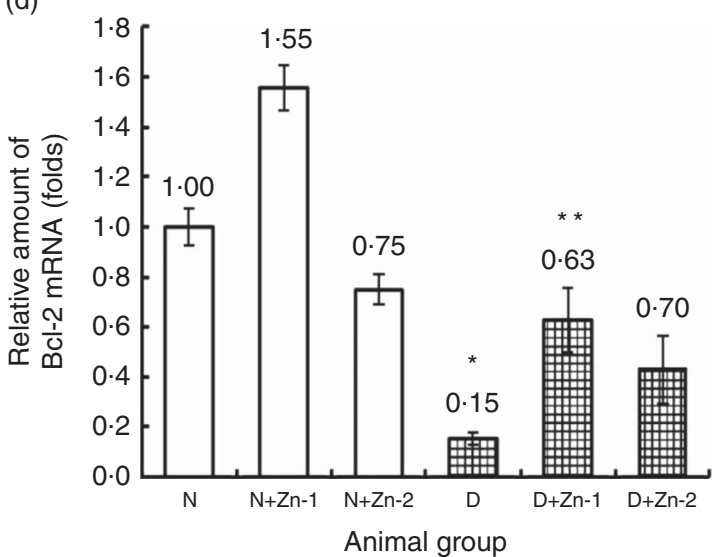

Fig. 8. Effect of zinc supplementation on the expressions of mRNAs in cardiac tissue fibrosis and apoptotic factors: (a) fibronectin, (b) collagen IV, (c) BCL2 associated $X$ protein (Bax) and (d) B-cell lymphoma 2 (Bcl-2) levels in diabetic rats. Values are means, with their standard errors for eight animals in each group. Relative gene expressions were normalised to $\beta$-actin levels and expressed in arbitrary units as fold change compared with uninfected controls. ${ }^{* * \star}$ Significantly different from the normal and diabetic control groups $(P<0.05)$. N, normal control; D, diabetic control; Zn-1, zinc supplemented at dose 1 ; Zn-2, zinc supplemented at dose 2.

of collagen fibres and myocardial fibrosis were evident in diabetic rats compared with normal control rats. Collagen sheets were fairly analogous to normal controls in the heart sections of the Zn-supplemented diabetic groups (Fig. 11).

Light microscopy of liver sections of diabetic rats stained by H\&E (Fig. 12) revealed severe dilatation and congestion in the central and portal veins concomitant with erosion and swelling in surrounding hepatocytes. Fibrosis in the periductal area of the bile duct and oedema in the portal area were detected. Focal inflammatory cells infiltrations, dilation of sinusoids as well as diffuse Kupffer cells proliferation were detected in between the degenerated hepatocytes compared with the normal control group. In contrast, the Zn-treated diabetic groups showed mild degenerative changes in the hepatocytes surrounding the central vein associated with congestion in the portal vein, mild fibrosis in the portal area with degeneration in surrounding hepatocytes and almost restored the complication due to diabetic stress (Fig. 12). PAS staining and Masson's trichrome staining were used for demonstrating glycogen and collagen, respectively. Significantly scarce and irregular pink positive materials (purple plaques) indicated glycogen depletion in the liver of diabetic rats, and this was almost restored in the Zn-supplemented groups (Fig. 12). Accumulation of collagen fibres (intensely blue coloured) and myocardial fibrosis in the liver of diabetic rats were confirmed by Masson's trichrome staining compared with that of normal control rats. Abundant collagens fibres were detected around the hepatic lobule, extended between the hepatocytes from the central vein or the portal tracts. Collagen sheets were equitably analogous to normal controls in the liver sections of $\mathrm{Zn}$-supplemented diabetic groups (Fig. 12).

\section{Discussion}

The present animal study has substantiated that $\mathrm{Zn}$ supplementation can partially ameliorate the severity of streptozotocin-induced oxidative stress in circulation as well as in cardiac and hepatic tissue. Induction of diabetes caused higher ROS generation, which consequently increased autoxidation of PUFA in lipids and amino acids in proteins as observed in plasma, heart and liver of diabetic animals. This observation concurs with a similar report in a previous study on the antioxidative influence of the fungal metabolite nigerloxin in diabetic rats from our laboratory ${ }^{(33)}$. Increased PC in different tissues and plasma of diabetic patients has been reported ${ }^{(34)}$. 
(a)

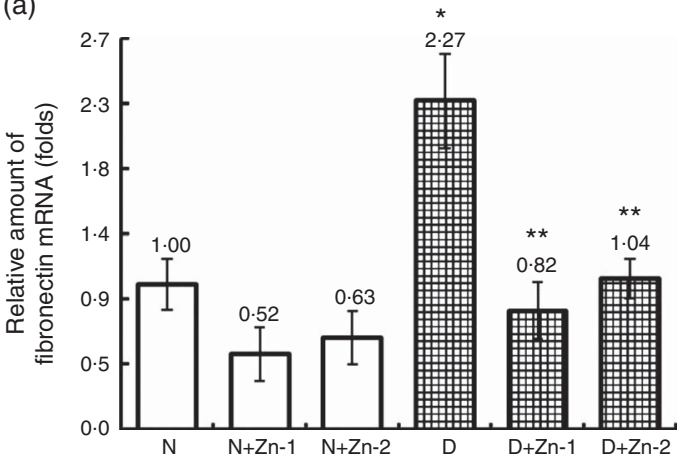

(b)

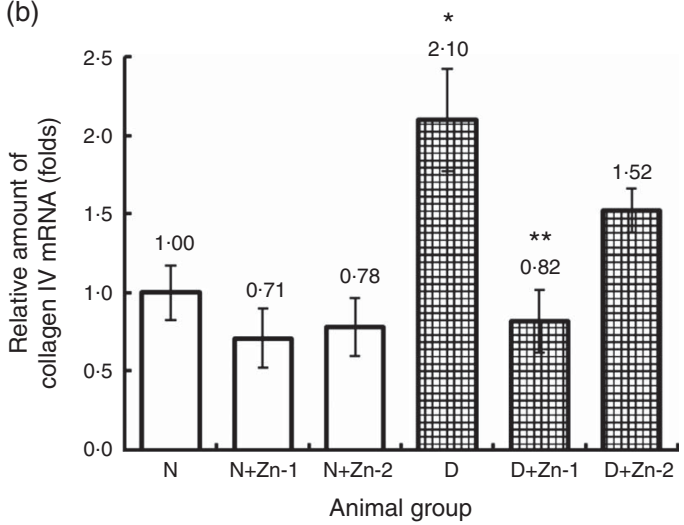

(c)

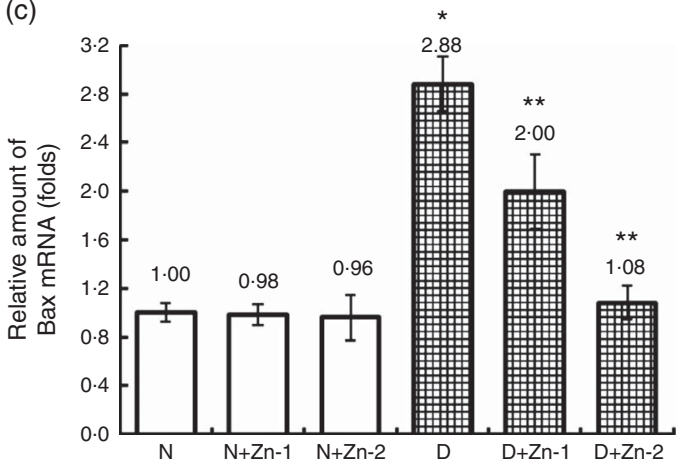

(d)

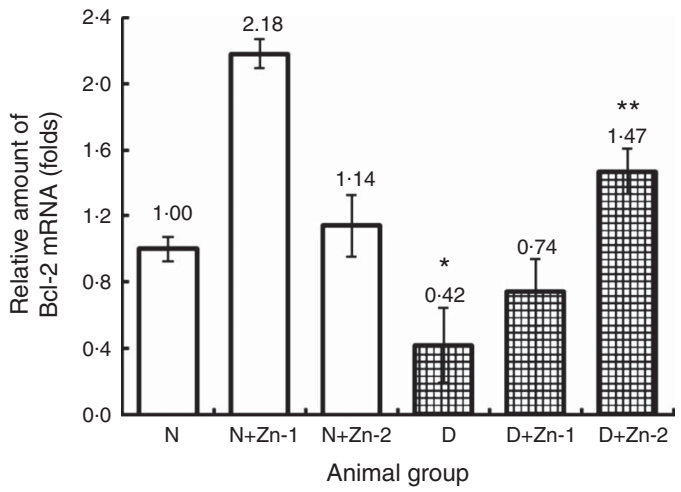

Fig. 9. Effect of zinc supplementation on the expressions of mRNAs in hepatic tissue fibrosis and apoptotic factors: (a) fibronectin, (b) collagen IV, (c) BCL2 associated X protein (Bax) and (d) B-cell lymphoma 2 (Bcl-2) in diabetic rats. Values are means, with their standard errors for eight animals in each group. Relative gene expressions were normalised to $\beta$-actin levels and expressed in arbitrary units as fold change compared with normal controls. ${ }^{* * *}$ Significantly different from the normal and diabetic control groups $(P<0.05)$. N, normal control; D, diabetic control; $\mathrm{Zn}-1$, zinc supplemented at dose $1 ; \mathrm{Zn}-2$, zinc supplemented at dose 2 .

(a)

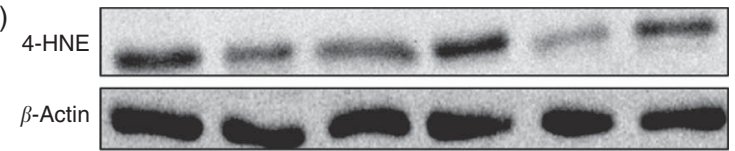

(b)

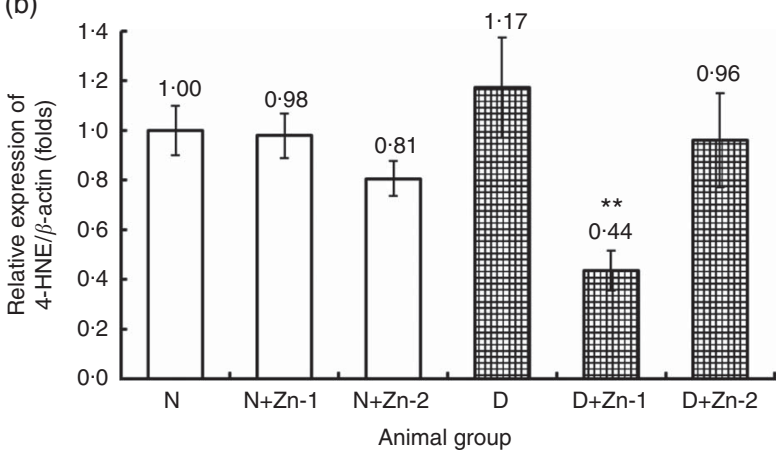

Fig. 10. Effect of zinc supplementation on cardiac lipid peroxide marker expression: (a) Western blot analysis of 4-hydroxy-2-nonenal (4-HNE) protein abundance in whole lysates of cardiac tissue in diabetic rats. (b) Relative expressions were normalised to $\beta$-actin levels and expressed in units as fold change compared with uninfected controls. Values are means, with their standard errors for eight animals in each group. ${ }^{* * *}$ Significantly different from the normal and diabetic control groups $(P<0.05)$. N, normal control; $\mathrm{D}$, diabetic control; Zn-1, zinc supplemented at dose $1 ; \mathrm{Zn}-2$, zinc supplemented at dose 2 .

Increased protein oxidation leads to decreased plasma albumin. Increased levels of ROS, MDA and PC were ameliorated by supplemental $\mathrm{Zn}$, which are suggestive of the antioxidant and free radical-scavenging properties of $\mathrm{Zn}$. Another mechanism that may also contribute to the antioxidant role of $\mathrm{Zn}$ is its ability to compete with transition metals $\mathrm{Fe}$ and $\mathrm{Cu}$ for the binding sites on the cell membrane. Fe and $\mathrm{Cu}$ ions catalyse the production of lipid peroxides, and thereby replacement of these metals by $\mathrm{Zn}$ in the plasma membrane could inhibit LPO in diabetic condition.

Overexpression of antioxidant enzyme activities in circulation might be a compensatory mechanism to prevent tissue damage under the oxidative stress triggered by diabetes. Increased oxidative stress markers (ROS, MDA and PC) were concomitant with diminished antioxidant scavengers - ascorbic acid and GSH - a substrate for GSH-linked enzymes. Increased activity of antioxidant enzymes in the blood of diabetic animals may be an adaptive mechanism. The adaptive elevation in plasma antioxidant enzyme activities was countered by $\mathrm{Zn}$ supplementation. The attendant elevated level of antioxidant molecules was corroborated with decreased levels of oxidative stress markers in the circulation as a result of $\mathrm{Zn}$ supplementation.

In the present study, activities of all the antioxidant enzymes in the cardiac tissue were increased, and the concentrations of antioxidant molecules were decreased in diabetic condition, which were substantiated with elevated oxidative stress markers. Zn supplementation restored the antioxidant status in the heart as suggested by the reduced oxidative stress markers. Increased antioxidant enzyme activity in diabetic animals may 

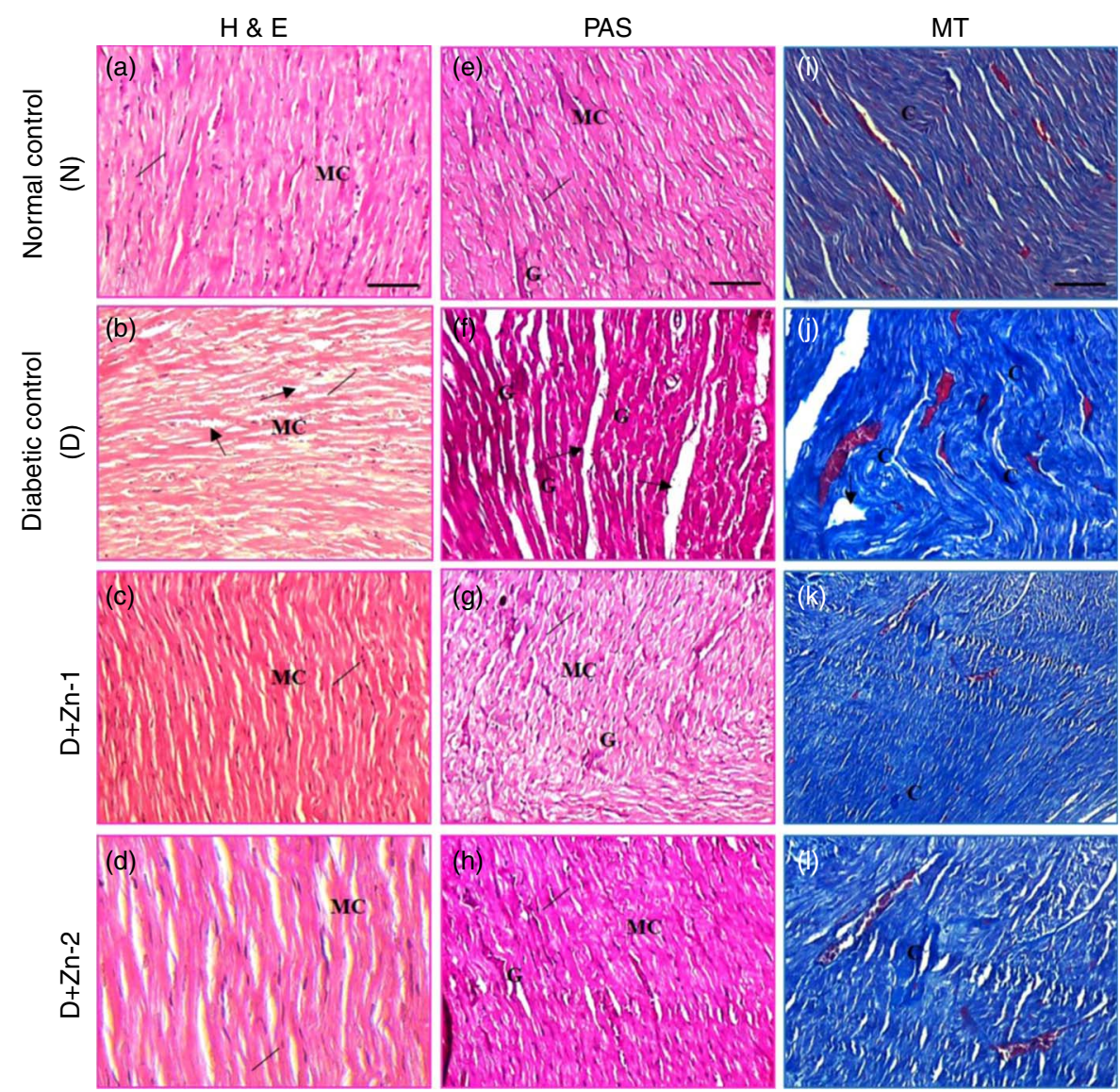

Fig. 11. Influence of zinc supplementation on heart histopathology in diabetic rats. (20x Representative haematoxylin-eosin (H\&E, a-d)-, periodic acid Schiff (PAS, e-h)and Masson's trichrome (MT, i-l)-stained images. N, normal control (a, e, i); diabetic control (D), (b, f, j); D + Zn-1 (dose-1), (c, g, k) and D + Zn-2 (dose-2) (d, h, l). MC, myocardial cells; $\longrightarrow$, nucleus; $\longrightarrow$, degenerative change; G, glycogen; C, collagen. A colour figure is available in the online version of the paper.

be due to the need for augmentation of generated ROS in diabetes-induced higher oxidative stress, which has been refurbished in the Zn-supplemented diabetic group concomitant with restored levels of antioxidant molecules and reduced cardiac oxidative stress markers. In this study, hepatic antioxidant enzymes and molecules were diminished by diabetic stress, in agreement with previous reports ${ }^{(33,35)}$. One potential mechanism for this reduction in antioxidant status may be due to glycation of enzyme proteins, which seems to be responsible for decreased affinity of this enzyme ${ }^{(36)}$. Decline in antioxidant status during diabetes makes tissues more susceptible to oxidative stress. The hepatic antioxidant enzyme activities were elevated by supplemental Zn intervention, concomitant with elevated levels of antioxidant molecules, which was corroborated with decreased levels of oxidative stress markers in the hepatic tissue.

Multiple mechanisms play a role in the pathogenesis of diabetic cardiomyopathy. Sustained hyperglycaemia may increase glycation of interstitial proteins such as collagen, which results in myocardial stiffness and impaired contractility ${ }^{(37)}$. Hyperglycaemia mediates tissue injury through the generation of ROS ${ }^{(38,39)}$. Hyperglycaemia leads to augmented glucose oxidation and mitochondrial generation of superoxide, which in turn leads to DNA impairment. In this study, myocardial damage was assessed by measuring the activity of the cardiac marker enzyme CK-MB, which is expressed in the heart muscle. Damage to myocardial cells containing CK-MB due to deficient oxygen supply during diabetic oxidative stress results in the leakage of this enzyme into plasma and its decreased activity in the heart ${ }^{(40)}$. Intracellular $\mathrm{Zn}$ levels are decreased in experimental rat hearts when exposed to ischaemia/reperfusion-induced myocardial injury, and $\mathrm{Zn}$ supplementation protects the heart ${ }^{(41)}$. In the present study, Zn supplementation significantly produced cardioprotection by decreasing the release of CK-MB in hyperglycaemic situation. In the present study, there was a significant elevation in the activities of plasma non-specific enzymes ALT and AST in diabetic rats, probably by decreasing the accumulation of amino acids.

Hyperlipidaemia regularly accompanies diabetes, which is characterised by increased levels of cholesterol, TAG and phospholipids. LDL comprises lipid species that are susceptible to oxidation in the presence of ROS in circulation ${ }^{(42)}$, and oxidative modification of LDL is a feature of atherosclerosis development. High urinary $\mathrm{Zn}$ excretion and congestive heart failure in diabetes mellitus has been reported ${ }^{(43)}$. Our study has shown that dietary $\mathrm{Zn}$ supplementation significantly reduced plasma LDL-cholesterol, TAG with a parallel decrease in liver 

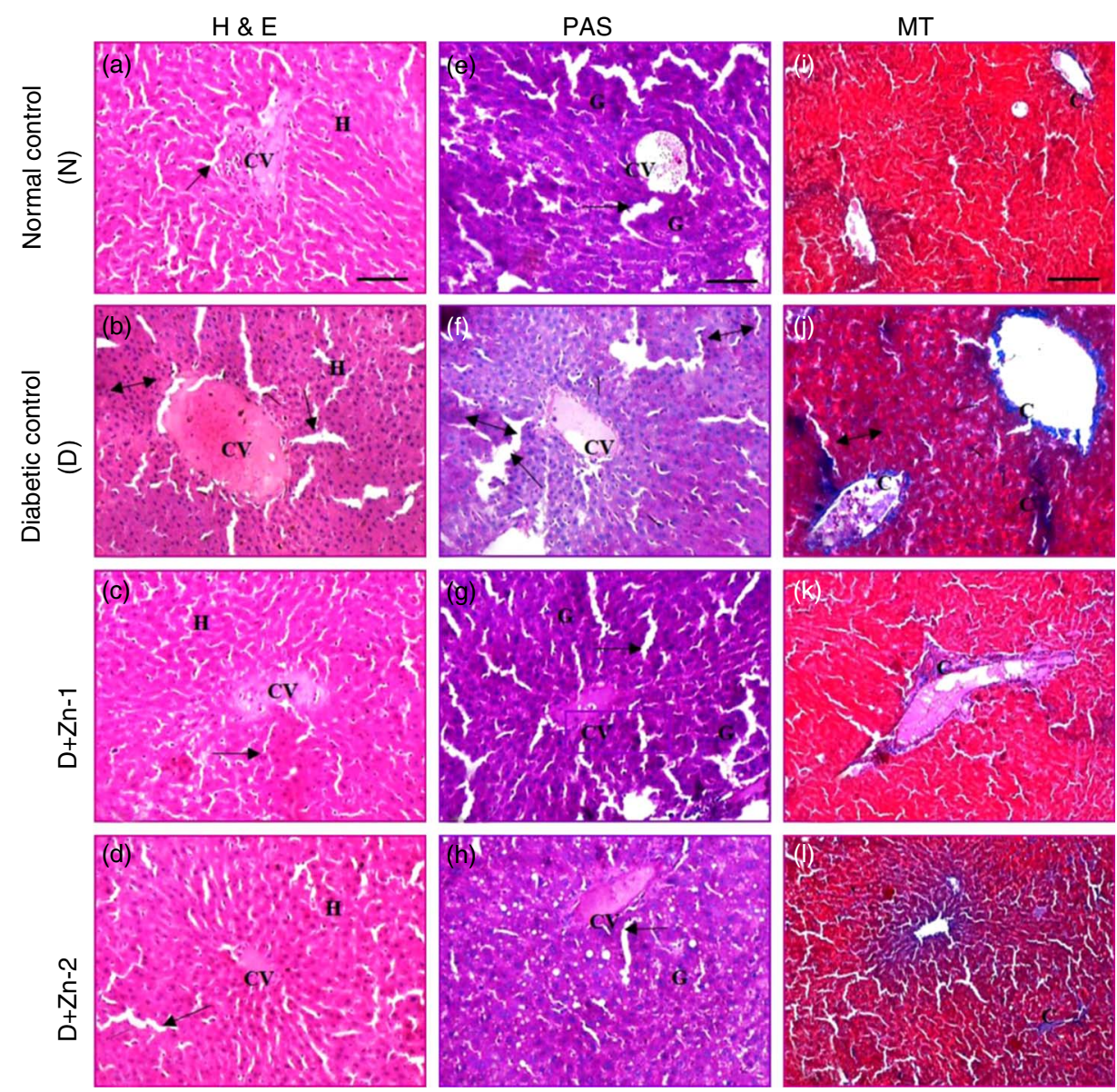

Fig. 12. Influence of zinc supplementation on liver histopathology in diabetic rats (20x Representative haematoxylin-eosin (H\&E, a-d)-, periodic acid Schiff (PAS, e-h)- and Masson's trichrome (MT, i-l)-stained images. N, normal control, (a, e, i); D, diabetic control (b, f, j); D+Zn-1 (dose-1), (c, g, k); D+Zn-2 (dose-2), $(\mathrm{d}, \mathrm{h}, \mathrm{l}) ; \mathrm{H}$, hepatocytes; CV, central vein; $\longrightarrow$, sinusoids; $\longleftrightarrow$, inflammatory foci; $\longrightarrow$, pyknotic (apoptotic) hepatocytes; G, glycogen; C, collagen. A colour figure is available in the online version of the paper.

and heart cholesterol and TAG, thus resulting in a beneficial lowering of the cholesterol:phospholipid ratio in cardiac and hepatic tissues. It is also suggested that $\mathrm{Zn}$ may have a protective role on the integrity of endothelial cells, which can rapidly uptake $\mathrm{Zn}$ by endocytosis of albumin-bound $\mathrm{Zn}$, and thus decrease vessel susceptibility to myocardial pathology ${ }^{(44)}$. Fatty acid profile was analysed in this study with the assumption that peroxidative loss of PUFA (mainly arachidonic acid) in diabetes due to increased LPO would result in their decrease. The amount of arachidonic acid (20:4) in the tissue of Zn-supplemented diabetic rats was significantly higher. This may be due to the antioxidant and free radical-scavenging properties of $\mathrm{Zn}$. Thus, the decreased ratio of unsaturated fatty acids and SFA existent in heart tissue was countered by $\mathrm{Zn}$ supplementation in diabetes.

During LPO, there will be overproduction of aldehydic products including 4-HNE, a most distinctive LPO product in diabetes. Overproduction of 4-HNE is due to peroxidation of $n-3$ and $n-6$ unsaturated fatty acids ${ }^{(45)}$, which is augmented by the oxidative stress-induced down-regulation of glutathione expression ${ }^{(46)}$ as found in our study. Stimulated 4-HNE synthesis leads to lipid peroxidative cardiac injury. Zn supplementation ameliorated
4-HNE accumulation by hindering lipid oxidation concomitant with up-regulation of glutathione expression.

Diabetic animals showed progressive cardiac fibrosis with increased collagen deposition. This is also supported by Masson's trichrome staining, suggesting that Zn supplementation could attenuate diabetes-induced fibroblast expression in rat heart. To assess the anti-apoptotic action of supplemental $\mathrm{Zn}$, we measured the levels of Bax (pro-apoptotic) and Bcl-2 (anti-apoptotic) proteins. The $\mathrm{Bcl}-2$ protein family plays an important role in the regulation of apoptosis. In response to pro-apoptotic stimuli, Bax can translocate from cytosol to mitochondria, resulting in mitochondrial cytochrome $\mathrm{C}$ discharge and stimulation of caspase- 9 and caspase- $3^{(47)}$. The present study has confirmed the augmented expression of Bax and declined Bcl-2 expression in diabetic cardiac tissue as reported earlier ${ }^{(48)}$. This similar amendment in Bax and Bcl-2 expression could be due to the response to hyperglycaemiainduced oxidative stress or TGF- $\beta$ stimuli. Our study indicated that this alteration was prevented by Zn treatment, presumably by antioxidant potential and by inhibiting TGF- $\beta$ up-regulation. Thus, Zn supplementation protects against apoptosis partially by restoring the balance of $\mathrm{Bax}$ and $\mathrm{Bcl}-2$ proteins. Suppression 
of the elevation of Bax and up-regulation of the expression of $\mathrm{Bcl}-2$ suggested that the anti-apoptotic effect of $\mathrm{Zn}$ was concomitant with regulation of the balance of $\mathrm{Bax}$ and $\mathrm{Bcl}-2$ mRNA expressions.

Diabetic cardiomyopathy is characterised by myocyte loss and fibrosis leading to decreased elasticity and impaired contractile function $^{(49)}$. Our study examined the downstream signalling, whereby hyperglycaemia-induced oxidative stress led to myocardial fibrosis, the most important pathogenetic factor of the heart's impaired function in diabetes consequent to structural and ultrastructural changes. Zn supplementation, by improving oxidative balance, countered the enhanced structural damage by increasing profibrogenic factors and restoring tissue levels of collagen IV and fibronectin in diabetic animals. Histological examination of cardiac and hepatic tissues showed that pathological changes that occurred due to diabetic complication were delineated by degenerated hepatocytes, cardiomyocytes, inflammatory infiltrations, altered distribution and deposition of glycogen and collagen fibres. Supplemental $\mathrm{Zn}$ rats showed noticeable restoration and nearly normalised structures of these tissues with a reduction in inflammatory infiltrations, number of necrotic cells and restored size and shape of nuclei. In diabetic animals, lipogenesis in hepatic tissue was decreased concomitantly with increased lipolysis, leading to stimulation of gluconeogenic enzymes. In Zn-fed rats, increased glycogen content in hepatic tissue might be due to reactivation of the glycogen synthase system as a result of increased insulin secretion ${ }^{(8)}$. In cardiac tissue of Zn-treated rats, decreased glycogen content might be due to the utilisation of cellular glucose occurring through elevated activities of glycolytic and NADP-linked lipogenic enzymes as in diabetic rat kidney ${ }^{(50)}$. Masson's trichrome staining of tissues showed significantly reduced collagen synthesis with $\mathrm{Zn}$ supplementation, which might be due to the inhibitory effect of collagen synthesis by $\mathrm{Zn}^{(51)}$

The beneficial effect of $\mathrm{Zn}$ supplementation was almost similar with either of the two doses tested in this study, with no higher benefit at the higher (10x normal) dose. Probably, the beneficial effect observed with $\mathrm{Zn}$ supplementation at five times the normal dose is around the maximum, and thus no further dose-dependent higher effect was discernible with ten times the normal dose. Further studies are warranted to understand the extent of excretory loss of body $\mathrm{Zn}$ during diabetes and the extent of absorption of dietary $\mathrm{Zn}$ given as a supplement through an improvement of the health and function of the gastrointestinal tract.

Thus, it is indicated that dietary $\mathrm{Zn}$ supplementation has a significant beneficial effect in experimental diabetic rat models. This study highlighted the potential ameliorative ability of supplemental Zn on hyperglycaemia-induced oxidative stress, hyperlipidaemia and protective influence against diabetes-induced hepatopathology and cardiopathology. Thus, Zn supplementation may offer a significant potential for clinical application in managing diabetes. These experimental findings might potentially translate to human wellness, especially with reference to diabetes and its various complications, which precipitate from unchecked oxidative stress. The amount of $\mathrm{Zn}$ used in this animal study can be applied to human studies. The application of the benefits of $\mathrm{Zn}$ supplementation in humans with diabetes, however, warrants clinical trials.

\section{Acknowledgements}

S. B. is grateful to the University Grants Commission, Government of India, New Delhi for the award of Senior Research Fellowship.

S. B. is responsible for all the benchwork involved in this study. The animal experiment and associated analytical studies were planned and supervised by K. S. who is also responsible for data interpretation and writing of this manuscript.

This research study was not supported by any external funding.

The authors declare that there are no conflicts of interest.

\section{References}

1. Sharma P, Jha A, Dubey RS, et al. (2012) Reactive oxygen species, oxidative damage, and antioxidativedefense mechanism in plants under stressful conditions. J Botany 2012, e217037.

2. Bandyopadhyay U, Das D \& Banerjee RK (1999) Reactive oxygen species: oxidative damage and pathogenesis. Curr Sci 77, 658-666.

3. Hruda J, Sramek V \& Leverve X (2010) High glucose increases susceptibility to oxidative-stress-induced apoptosis and DNA damage in K-562 cells. Biomed Pap Med Fac Univ Palacky Olomouc Czech Repub 154, 315-320.

4. Saxena AK, Srivastava P, Kale RK, et al. (1993) Impaired antioxidant status in diabetic rat liver: effect of vanadate. Biochem Pharmacol 45, 539-542.

5. De Marchi E, Baldassari F, Bononi A, et al. (2013) Oxidative stress in cardiovascular diseases and obesity: role of p66Shc and protein kinase C. Oxid Med Cell Longev 2013, e564961.

6. Foster M \& Samman S (2010) Zinc and redox signaling: perturbations associated with cardio vascular disease and diabetes mellitus. Antioxid Redox Signal 13, 1549-1573.

7. Chausmer AB (1998) Zinc, insulin and diabetes. J Am Coll Nutr 17, 109-115.

8. Barman S \& Srinivasan K (2016) Zinc supplementation alleviates hyperglycemia and associated metabolic abnormalities in streptozotocin-induced diabetic rats. Can J Physiol Pharmacol 94, 1356-1365.

9. Prasad AS (2008) Zinc in human health: effect of zinc on immune cells. Mol Med 14, 353-357.

10. Prasad AS (2013) Biochemistry of Zinc. New York: Springer Science \& Business Media.

11. Jayawardena R, Ranasinghe P, Galappatthy P, et al. (2012) Effects of zinc supplementation on diabetes mellitus: a systematic review and meta-analysis. Diabetol Metab Syndr 4, 13.

12. Huggett AS \& Nixon DA (1957) Use of glucose oxidase, peroxidase, and $o$-dianisidine in determination of blood and urinary glucose. Lancet $\mathbf{2 7 3}, 368-370$.

13. LeBel CP, Ischiropoulos H \& Bondy SC (1992) Evaluation of the probe $2^{\prime}, 7^{\prime}$-dichloro fluorescin as an indicator of reactive oxygen species formation and oxidative stress. Chem Res Toxicol 5, 227-231.

14. Driver AS, Kodavanti PR \& Mundy WR (2000) Age-related changes in reactive oxygen species production in rat brain homogenates. Neurotoxicol Teratol 22, 175-181.

15. Yagi K (1984) Assay for blood plasma or serum. Methods Enzymol 105, 328-331.

16. Ohkawa H, Ohishi N \& Yagi K (1979) Assay for lipid peroxides in animal tissues by thiobarbituric acid reaction. Anal Biochem 95, 351-358.

17. Reznick AZ \& Packer L (1994) Oxidative damage to proteins: spectrophotometric method for carbonyl assay. Methods Enzymol 233, 357-363.

18. Flohé L \& Otting F (1984) Superoxide dismutase assays. Methods Enzymol 105, 93-104. 
19. Aebi H (1984) Catalase in vitro. Methods Enzymol 105, 121-126.

20. Flohé L \& Günzler WA (1984) Assays of glutathione peroxidase. Methods Enzymol 105, 114-121.

21. Carlberg I \& Mannervik B (1985) Glutathione reductase. Methods Enzymol 113, 484-490.

22. Warholm M, Guthenberg C, von Bahr C, et al. (1985) Glutathione transferases from human liver. Methods Enzymol 113, 499-504.

23. Beutler E, Duron O \& Kelly BM (1963) Improved method for the determination of blood glutathione. J Lab Clin Med $\mathbf{6 1}$, 882-888.

24. Omaye ST, Turnbull JD \& Sauberlich HE (1979) Selected methods for the determination of ascorbic acid in animal cells, tissues, and fluids. Methods Enzymol 62, 3-11.

25. Kind PRN \& King EJ (1954) Estimation of plasma phosphatase by determination of hydrolysed phenol with amino-antipyrine. J Clin Pathol 7, 322-326.

26. Lowry $\mathrm{OH}$, Rosebrough NJ, Farr AL, et al. (1951) Protein measurement with the folin phenol reagent. J Biol Chem $\mathbf{1 9 3}$ 265-275.

27. Folch J, Lees M \& Stanley GHS (1957) A simple method for the isolation and purification of total lipides from animal tissues. $J$ Biol Chem 226, 497-509.

28. Searcy RL \& Bergquist LM (1960) A new color reaction for the quantitation of serum cholesterol. Clin Chim Acta 5, 192-199.

29. Warnick GR \& Albers JJ (1978) A comprehensive evaluation of the heparin-manganese precipitation procedure for estimating high density lipoprotein cholesterol. J Lipid Res 19, 65-76.

30. Stewart JCM (1980) Colorimetric determination of phospholipids with ammonium ferro thiocyanate. Anal Biochem 104, 10-14.

31. Fletcher MJ (1968) A colorimetric method for estimating serum triglycerides. Clin Chim Acta 22, 393-397.

32. Bowyer DE, Leat WMF, Howard AN, et al. (1963) The determination of the fatty acid composition of serum lipids separated by thin-layer chromatography; and a comparison with column chromatography. Biochem Biophys Acta 70, 423-431.

33. Suresha BS, Vasantha KY, Sattur AP, et al. (2012) Beneficial influence of fungal metabolite nigerloxin on diabetes-induced oxidative stress in experimental rats. Can J Physiol Pharmacol 91, 149-156.

34. Pandey K, Mishra N \& Rizvi SI (2010) Protein oxidation biomarkers in plasma of type 2 diabetic patients. Clin Biochem 43, 508-511.

35. Maritim AC, Sanders RA \& Watkins JB (2003) Diabetes, oxidative stress, and antioxidants: a review. $J$ Biochem Mol Toxicol 17, 24-38

36. Muruganandam A, Drouillard C, Thibert RJ, et al. (1992) Glutathione metabolic enzyme activities in diabetic platelets as a function of glycemic control. Thromb Res $\mathbf{6 7}$, 385-397.
37. Avendano GF, Agarwal RK, Bashey RI, et al. (1999) Effects of glucose intolerance on myocardial function and collagenlinked glycation. Diabetes 48, 443-447.

38. Du X, Matsumura T, Edelstein D, et al. (2003) Inhibition of GAPDH Activity by poly(ADP-ribose) polymerase activates three major pathways of hyperglycemic damage in endothelial cells. J Clin Invest 112, 1049-1057.

39. Nishikawa T, Edelstein D, Du XL, et al. (2000) Normalizing mitochondrial superoxide production blocks three pathways of hyperglycaemic damage. Nature 404, 787-790.

40. Mitra B \& Panja M (2005) Myocardial metabolism: pharmacological manipulation in myocardial ischaemia. I Assoc Physicians India 53, 552-560.

41. Karagulova G, Yue Y, Moreyra A, et al. (2007) Protective role of intracellular zinc in myocardial ischemia/ reperfusion is associated with preservation of protein kinase C isoforms. J Pharmacol Exp Therap 321, 517-525.

42. Cyrus T, Praticò D, Zhao L, et al. (2001) Absence of 12/15lipoxygenase expression decreases lipid peroxidation and atherogenesis in apolipoprotein E-deficient mice. Circulation 103, 2277-2282.

43. Shokrzadeh M, Ghaemian A, Salehifar E, et al. (2009) Serum zinc and copper levels in ischemic cardiomyopathy. Biol Trace Elem Res 127, 116-123.

44. Bernal PJ, Bauer EM, Cao R, et al. (2011) A role for zinc in regulating hypoxia-induced contractile events in pulmonary endothelium. Am J Physiol Lung Cell Mol Physiol 300, L874-L886.

45. Ayala A, Munoz MF \& Arguelles S (2014) Lipid peroxidation: production, metabolism, and signaling mechanisms of malondialdehyde and 4-hydroxy-2-nonenal. Oxid Med Cell Longevity 2014, May, e360438.

46. Liu RM, Vayalil PM, Ballinger C, et al. (2012) Transforming growth factor B suppresses glutamate-cysteine ligase gene expression and induces oxidative stress in a lung fibrosis model. Free Rad Biol Med 53, 554-563.

47. Lee HJ, Lee HJ, Lee EO, et al. (2008) Mitochondriacytochrome C-caspase-9 cascade mediates isorhamnetininduced apoptosis. Cancer Lett 270, 342-353.

48. Srinivasan S, Stevens M \& Wiley JW (2000) Diabetic peripheral neuropathy: evidence for apoptosis and associated mitochondrial dysfunction. Diabetes 49, 1932-1938.

49. Aragno M, Mastrocola R, Alloatti G, et al. (2008) Oxidative stress triggers cardiac fibrosis in the heart of diabetic rats. Endocrinology 149, 380-388.

50. Haritha C, Gopalareddy A, Ramanareddy Y, et al. (2013) Evaluation of protective action of fenugreek, insulin and glimepiride and their combination in diabetic sprague dawley rats. J Nat Sci Biol Med 4, 207-212.

51. Shi F, Sheng Q, Xu X, et al. (2015) Zinc supplementation suppresses the progression of bile duct ligation-induced liver fibrosis in mice. Exp Biol Med 240, 1197-1204. 